\title{
Skill Mix and Patient Outcomes: A Multi-country Analysis of Heart Disease and Breast Cancer Patients
}

DOI:

10.1016/j.healthpol.2020.07.009

\section{Document Version}

Accepted author manuscript

Link to publication record in Manchester Research Explorer

\section{Citation for published version (APA):}

Kopasker, D., Islam, M. K., Gibson, J., Lau, Y., Sutton, M., Askildsen, J. E., Bond, C., \& Elliott, R. (2020). Skill Mix and Patient Outcomes: A Multi-country Analysis of Heart Disease and Breast Cancer Patients. Health Policy. https://doi.org/10.1016/j.healthpol.2020.07.009

\section{Published in:}

Health Policy

\section{Citing this paper}

Please note that where the full-text provided on Manchester Research Explorer is the Author Accepted Manuscript or Proof version this may differ from the final Published version. If citing, it is advised that you check and use the publisher's definitive version.

\section{General rights}

Copyright and moral rights for the publications made accessible in the Research Explorer are retained by the authors and/or other copyright owners and it is a condition of accessing publications that users recognise and abide by the legal requirements associated with these rights.

\section{Takedown policy}

If you believe that this document breaches copyright please refer to the University of Manchester's Takedown Procedures [http://man.ac.uk/04Y6Bo] or contact uml.scholarlycommunications@manchester.ac.uk providing relevant details, so we can investigate your claim.

\section{OPEN ACCESS}




\title{
Skill Mix and Patient Outcomes: A Multi-country Analysis of Heart Disease and Breast Cancer Patients
}

\author{
Daniel Kopasker*1; M. Kamrul Islam²; Jonathan Gibson³ Yiu-Shing Lau ${ }^{3}$; Matt Sutton 3 ; Jan \\ Erik Askildsen $^{2}$; Christine Bond ${ }^{4}$; Robert Elliott ${ }^{1}$; on behalf of the MUNROS team.
}

\footnotetext{
*Corresponding author: Daniel Kopasker, Health Economics Research Unit, University of Aberdeen, Polwarth Building, Foresterhill, AB25 2ZD, UK. Email: daniel.kopasker@abdn.ac.uk

${ }^{1}$ Health Economics Research Unit (HERU), University of Aberdeen, UK.

${ }^{2}$ Department of Economics, University of Bergen, Norway.

${ }^{3}$ Division of Population Health, Health Services Research \& Primary Care, University of Manchester, UK

${ }^{4}$ Institute of Applied Health Sciences, University of Aberdeen, UK.
}

\section{Acknowledgments:}

The authors also wish to thank Jan Abel Olsen and participants at the 2019 winter meeting of the Health Economists' Study Group for helpful comments on an earlier draft of this paper. We would also like to thank all those who supported and guided this work both within the MUNROS research project team and as members of the external advisory board. The European Commission funded this research programme 'Healthcare Reform: The iMpact on practice, oUtcomes and cost of New ROles for health profeSsionals (MUNROS), under the European Community's Seventh Framework Programme (FP7 HEALTH-2012-INNOVATION-1) grant agreement number HEALTH-F3-2012305467EC. HERU is supported by the Chief Scientist Office (CSO) of the Scottish Government Health and Social Care Directorates (SGHSC). The views expressed here are those of the Unit and not necessarily those of the CSO. 


\section{Highlights}

Variations in skill mix are associated with positive and adverse patient outcomes.

A task component-based measure of skill mix is used.

Novel skill mix measure is specific to a care pathway.

Influence of skill mix on outcomes varies across pathways.

Some evidence of consistent effect across health systems within pathway. 


\title{
Skill Mix and Patient Outcomes: A Multi-country Analysis of Heart Disease and Breast Cancer Patients
}

\begin{abstract}
:
Policymakers are becoming aware that increasing the size of the healthcare workforce is no longer the most viable way to address the increasing demand for healthcare. Consequently, a focus of recent healthcare workforce reform has been extending existing roles and creating new roles for health professionals. However, little is known of the influence on outcomes from this variation in labour inputs within hospital production functions. Using a unique combination of primary and administrative data, this paper provides evidence of associations between the composition of care delivery teams and patient outcomes. The primary data enabled the construction of a task component-based measure of skill mix. This novel measure of skill mix has the advantage of capturing how workforce planning can restructure the relative input of nurses or physicians into task components while keeping the overall level of staff fixed. The analysis focuses on specific care pathways and individual hospitals, thus controlling for an under-investigated source of heterogeneity. Additionally, stratifying by country (England, Scotland, and Norway) enabled analysis of skill mix within different health systems. We provide evidence that variations in labour inputs within the breast cancer and heart disease care pathways are associated with both positive and adverse outcomes. The results illustrate the scope for substitution of task components within care pathways as a potential method of healthcare reform.
\end{abstract}

Keywords: Skill mix, substitution, health workforce, patient outcomes, production function.

JEL classification: J24, D24, H51, I10 


\section{Introduction}

In many European countries expenditure on health is the largest single item of public spending (Hernandez et al. 2006). The size and composition of the healthcare workforce contribute substantially to both expenditure levels and the performance of healthcare systems (Dixon et al. 2018). In attempts to contain healthcare expenditures and improve performance, these key characteristics of the healthcare workforce are changing in many European countries (Maier et al., 2018).

Policymakers are becoming aware that simply increasing the size of the healthcare workforce is no longer a viable option to address the challenges of managing the healthcare needs of ageing populations; the existing workforce must be restructured to change how services are delivered (Scottish Government, 2016). A key focus has been to develop the skills of the healthcare workforce by extending existing roles and creating new roles for health professionals. This focus implicitly assumes that lower skilled/cost staff can substitute for higher skilled/cost staff without adversely affecting patient outcomes. Yet little is known about the impact of such innovations in healthcare delivery systems on specific patient outcomes. This paper attempts to address this lack of evidence by investigating whether differences in the composition of the care delivery team are associated with different process, healthcare use, and medical outcomes. For a consistent patient sample, we assess relative efficiency, in terms of the length of inpatient stays, and the quality of care (emergency readmission rates and survival probability) associated with variations in skill mix.

Hospitals are in essence multi-product firms, and there is no foundation to believe that the production functions are common across care pathways. To address potential heterogeneity across pathways, we separately analyse two conditions which have a high societal burden breast cancer and heart disease (STEMI - elevated ST wave myocardial infarction). Some notable contributions, such as Martin et al. (2015) and Street et al. (2014), have reported pathway specific analyses of patient outcomes, but these have not investigated the role of skill mix at this level of disaggregation. Our analysis focuses on this gap in the literature.

An important feature of the breast cancer and STEMI care pathways is that they are determined by international protocols and guidelines (Blank and Burau, 2013). Therefore, we can reliably assume that different hospitals, both within and between the three northern European health systems which are the focus of this study, are delivering this care using broadly the same procedures. This feature enabled disaggregation of the care pathways into task components and collection of primary data from healthcare professionals regarding which tasks they are involved in delivering. From these responses a hospital and pathway-specific measure 
of skill mix was constructed by Gibson and Sutton (2019). The Measure of Relative Nurse Involvement (MORNI) (Gibson and Sutton, 2019) measures the relative labour input of nurses and physicians on a care pathway, and thus, captures the extent of task component substitution - nurses doing components of tasks elsewhere performed by physicians. Using the MORNI, we assess the relative performance of different mixtures of labour inputs in the hospital production function.

A further feature of the breast cancer and STEMI care pathways is that individual-level administrative data on outcomes are routinely collected within the three distinct health systems analysed (Scotland, Norway, and England). This enables us to control for the influence of patient diversity on outcomes, another important source of heterogeneity between hospitals.

The combination of administrative and primary data generates a unique dataset to examine the pathway-specific influence of skill mix on patient outcomes. We show that variation in skill mix along care pathways is associated with both positive and adverse patient outcomes. Consistent with the "quicker and sicker" argument (Kosecoff et al., 1990), efficiency gains may come at the cost of reductions in survival probability on some care pathways.

The next section introduces our conceptual framework. Section 3 briefly reviews the relevant literature. Section 4 provides our methodology. Section 5 contains regression results. Section 6 provides discussion and Section 7 concludes.

\section{Conceptual Framework}

The focus of this paper is how the mix of labour inputs into task components influences the outputs, the measured patient outcomes, of hospitals within two care pathways in each of the three countries. It is known that hospital production functions are labour intensive and involve healthcare professionals with varying levels of skill. Any care pathway can be broken down into the task components which must be completed to produce the output of the overall care pathway. Between task components the level of skill required by the health professional will vary, and each of these task components will have an output.

To conceptualise the decision faced by health service workforce planners it is useful to consider how task components combine within the production function for a care pathway. We frame our discussion of the hospital production using elements of models by Acemoglu and Autor (2011) and Koch (2015). Although the production functions in these models are not specific to hospitals, they are task-specific, involve labour inputs from staff with varying levels of skill, and are aggregated to form the final output. 
The patient outcome we observe following treatment results from the aggregation of outputs from multiple task components completed by nurses and physicians. Each care pathway involves a combination of a continuum of task components represented by the unit interval. The combination of task components varies across pathways, but is consistent within pathways and between hospitals. The production of outcomes on a care pathway can be formalised to express how task components are combined:

$$
Y(h)=\phi(h) \exp \left[\int_{0}^{1} \ln y(h, i) d i\right]
$$

where $Y(h)$ is the patient outcome for hospital $h$ on a single care pathway, $\phi(h)$ is a hospital's efficiency in workforce planning (allocating task components to staff), $y(h, i)$ is the production level of task component $i$ in hospital $h$.

To enhance the clarity of our conceptual framework we simplify the healthcare workforce such that only two types of labour exist, and these types are determined by skill levels. Task components are performed by low-skilled and high-skilled workers, $n(h, i)$ and $p(h, i)$ respectively. Higher skilled workers $(p)$ represent physicians and are employed at a wage of $w_{p}$. Lower skilled workers $(n)$ represent nurses and are employed at a lower wage of $w_{n}$. The supply of both types of worker is fixed and inelastic. Capital is assumed to be fixed and factor neutral for all task components. The factors of production combine in a linear homogenous task component-specific production function:

$$
y(h, i)=\alpha_{n}(i) n(h, i)+\alpha_{p}(i) p(h, i)
$$

where $\alpha_{n}(i)$ and $\alpha_{p}(i)$ are the labour productivities of the two skill types, when performing task component $i$. These capture how the comparative advantage of skill groups differs across task. Grades of staff differ in their abilities performing a single task component, and task components differ in their skill requirements. Consequently, the scope for substitution between task components will vary based upon the competencies required. A high skilled worker assigned to the least complex task component will likely be as productive as a low-skilled worker, since specific skills are not required for performing the task component. The productivity advantage of high skilled workers increases with the complexity of task components. Where a binding budget constraint exists, such as within many healthcare systems, the workforce planner will seek to utilise this marginal rate of technical substitution between grades of staff until it equals the factor-price ratio. At this point the efficient assignment of staff will be achieved. 
The task component production function implies that there is scope for substitution between nurses and physicians in the performance of task components. This would allow the workforce planner to alter the relative input of nurses and physicians to specific task components without altering the overall numbers of nurses and physicians involved on the care pathway. For example, by adjusting the proportion of relatively low-skilled task components within the workload of physicians, where the comparative advantage of physicians over nurses is smallest, this could increase the resources available to produce high-skilled task components.

In this simplified hospital production function, outputs (patient outcomes) are held constant at the point where skill substitution occurs. However, process, healthcare use, and medical outcomes may differ in their relationship to the labour inputs of the hospital production function. We investigate the assumption of constant outputs in our empirical analyses.

While this conceptualisation of the planner's decision simplifies the hospital production function, it is a useful foundation for understanding the issue and is the implicit basis for many of the empirical studies discussed below. If the outcomes of the production function remain constant regardless of the skill mix employed, there is scope to substitute tasks from one skill type to another. For example, from high cost staff to lower cost staff. If outcomes change, either improving or deteriorating, health care planners must trade the magnitude of the changes. For example, efficiency against survival. Such knowledge is essential for informed decision making if healthcare systems are to meet the increasing demand for health services and manage financial pressures. Within this paper we investigate the scope for substitution of tasks between nurses and physicians without adversely affecting patient outcomes. We do this using a measure of skill mix (labour inputs) which is disaggregated to the care pathway level.

\section{Related Literature}

A small number of empirical papers, mainly from the US, have focused on nurses only when investigating the effect of skill mix on patient outcomes at the health system level. Griffiths et al. (2014) provides a comprehensive review. These studies often show that lowering nursing skill mix, that is replacing professional nurses with less qualified nurses, is associated with higher rates of adverse outcomes. Needleman et al. (2002) use hospital-level administrative data on staffing levels and patient discharges from a large sample of hospitals across 11 states. The measure of skill mix used was the proportion of hours of nursing care provided by each skill category of nursing personnel. They find that higher skill mix was associated with shorter length of stay for medical patients, but no significant association was 
found for surgical patients. For both patient types a lower skill mix was associated with higher rates of some infections. Using the same measure of skill mix in a study including 54 US hospitals, Blegen et al (2011) also found that lower skill mix was associated with higher infection rates, and additionally with increased in-hospital mortality. Only one US study found an association between nursing skill mix and readmission rates, which were found to be lower when the labour input of registered nurses was higher (Weiss et al., 2011).

Two Canadian studies examining factors determining casemix-adjusted 30-day mortality rates within hospitals identified a negative association between 30-day mortality and registered nurses as a percentage of the total nursing staff within a hospital (Estabrooks et al., 2005, and Tourangeau et al., 2006). One study based on English National Health Service examine the relationship between daily levels of registered nurse and nursing assistant staffing and hospital mortality (Griffiths et al., 2019). They found that lower levels of registered nurse staffing were associated with increased risk of mortality. Likewise, a broad review of nurse staffing, skill mix, and patient outcomes identified a consistent association between lower registered nurse staffing levels, increased mortality and other adverse patient outcomes (Griffiths et al., 2016).

Aiken et al (2017) pooled data from 6 countries and 188 hospitals (Belgium, England, Finland, Ireland, Spain and Switzerland). They measured skill mix at the hospital-level by the percentage of professional nurses (at least 10 years of general education at the secondary level plus 3 years of nursing education) among all nursing personnel using data from a nursing survey. The relevant question asked nurses to self-report the number and qualifications of nursing staff on their last shift. Consistent with the US studies, Aiken et al. (2017) find that lower skill mix is associated with higher odds of inpatient mortality and other adverse events, such as infections.

We make several contributions to this literature. Firstly, by focusing on both specific care pathways and individual hospitals our analysis controls for a great deal of heterogeneity in health systems and across pathways within hospitals. For example, a higher skill mix may be a feature of particularly complex care pathways and the share of total hospital activity accounted for by such pathways may differ between hospitals. In addition, by stratifying our analysis at the country level we can assess variation in the influence of skill mix within different health system settings. Lastly, our measure of skill mix is novel since it is based on task components and compares the relative input by physicians and nurses. This enables an assessment of the scope for substitution between nurses and physicians. 


\section{Methodology}

This study employs a unique combination of primary and administrative data. Primary data was collected as part of the wider MUNROS (www.abdn.ac.uk/munros) project. Within one part of the project, questionnaires were self-completed by healthcare professionals at participating hospitals in each of the countries involved in the study. This enabled a pathwayspecific measure of the skill mix within the care delivery team to be constructed. Detailed discussion of the primary data collection is available in Bond et al. (2016).

A care pathway is defined as a group of tasks to be performed in addressing the needs of a patient requiring treatment for a defined clinical condition within a hospital. As a result of discussions with clinicians, the questionnaire used within the MUNROS project disaggregated stages of care (e.g. diagnosis) into tasks (e.g. patient assessment) and then smaller task components (e.g. conducting coronary angiography) involved in the delivery of care. The complete task lists are available within the appendix.

The breast cancer care pathway covers four stages: diagnosis (6 tasks and 29 task components), surgery or managing therapy ( 5 tasks and 38 task components), follow up and/or managing complications ( 5 tasks and 21 task components), and palliative care ( 1 task and 4 task components).

The heart disease care pathway covers five stages: diagnosis and assessment (4 tasks and 15 task components), providing treatment ( 3 tasks and 11 task components), managing complications ( 1 task and 7 task components), cardiac rehabilitation (2 tasks and 6 task components), and care post-discharge (4 tasks and 12 task components).

Health professionals were asked to indicate their job title and if they were involved in the delivery of each task component along the care pathway. Substantial effort was made to ensure consistent categorisation of staff. Respondents were asked to report their job title and level of education. Using information from both questions, the respondents were assigned to one of 28 predefined professions by two researchers in each country. The same categories were used for all countries surveyed in the wider MUNROS project. Any differences in categorisation were discussed with the research group to ensure consistency. Only physicians (consultants and junior doctors) and nursing staff (advanced nurses, specialist nurses, and general nurses) actively involved in hospital-based care for breast cancer or STEMI are used within this analysis. Data constraints prevented greater staff category disaggregation, and the inclusion of primary care and allied health professionals (15 categories). However, the 
excluded staff categories will have limited involvement in inpatient stays, the focus of our analysis.

Response rates from health care professionals involved on the breast cancer pathway were $43 \%$ in Scotland, $45 \%$ in Norway, and 51\% in England. For STEMI the equivalent figures were $34 \%$ in Scotland, $54 \%$ in Norway, and $47 \%$ in England.

Questionnaire responses on involvement in task components were then used to form our main variable of interest - the MORNI. Although certain task components may require input from only one skill level, all task components are included in the skill mix calculation since the output we observe involves aggregation over the care pathway. The method for forming the MORNI is summarised below. For a detailed discussion of the MORNI development see Gibson and Sutton (2019). The determinants of changes in professional roles are not examined in this paper, a discussion of these issues can be found in Köppen et al. (2018).

Administrative data detailing hospital admissions, outcomes and characteristics at the patient-level (described below) for Scotland was extracted and linked by the Information Services Division (ISD) of NHS Scotland. Equivalent data for England was sourced from the Hospital Episodes Statistics (HES), while Norwegian data comes from the Norwegian Patient Registry (NPR). We also include routine data on hospital characteristics and performance which are publicly available.

Our dataset covers all inpatients with a new diagnosis for breast cancer and STEMI at participating hospitals in the calendar year 2013. We reduce the scope for treatment heterogeneity by applying strict conditions for inclusion in the sample. These are International Classification of Disease (ICD10) codes 21.0, 21.1, 21.2, and 21.3 for STEMI, and ICD10 code C50 for initially surgically managed breast cancer.

An inpatient stay is defined as a period of treatment requiring the patient to remain in hospital for a minimum of 1 night. The breast cancer samples cover seven hospitals in Scotland, six in Norway, and nine in England. For STEMI twelve Scottish hospitals are included, seven from Norway, and nine from England.

Individuals often appear multiple times within the inpatient records since these are predominantly recorded at the episode level. Within the raw data a single period of treatment may appear as multiple episodes, mainly for administrative reasons, since an episode can be defined in several ways. Examples include when an inpatient becomes a day patient in another specialty during the inpatient stay, when a transfer between hospitals occurs, or when there is a change in consultant for medical reasons. Since we are interested in the effect of skill mix over the pathway, this method of recording episodes may distort two of our outcome variables - 
length of inpatient stay and emergency readmission within 28 days of discharge. For example, if an inpatient's condition changes to such an extent that a different consultant is needed, this may be mistakenly recorded as an emergency readmission despite discharge and readmission occurring on the same day and the patient not leaving hospital. Busby et al. (2017) show, using the HES, that the length of stay is often underestimated when using episode-level data. For these reasons, we structure our dataset at the level of a continuous inpatient stay (CIS). A CIS constitutes a single period of treatment for an individual but may be formed from multiple episodes. Individuals may have more than one CIS within a calendar year, and so could appear multiple times within our dataset. To limit the influence of relatively rare cases involving a change in speciality or hospital, we restrict our sample such that the longest single episode within a CIS relates to the care pathways of interest and assign hospital-level variables based on the location of the longest episode within a CIS.

\section{Empirical strategy}

Governance restrictions on the administrative data used within the study meant that it was not possible to pool data from the three countries. Consequently, we estimated parallel models for the individual countries. We estimate a zero-truncated negative binomial (ZTNB) regression for the outcome based on counts (length of a CIS) and a probit regression for our dichotomous outcome variables (28-day emergency readmission following discharge and 30day survival post-admission). In all cases heteroskedasticity robust standard errors are used. Models were estimated using the tnbreg and probit commands in Stata 15. The model estimated is as follows:

$$
\text { Outcome }_{i h p}=\alpha_{0}+\alpha_{1} \text { MORNI }_{h p}+X_{h}^{\prime} \beta+Y_{i}^{\prime} \theta+\varepsilon_{i h p}
$$

where Outcome $i h p$ is the treatment outcome for individual $i$ in hospital $h$ on care pathway $p$ in 2013, MORNI is the hospital and pathway specific skill mix, $X$ is a vector of hospital characteristics (teaching hospital dummy, median waiting time for elective treatment, and 30day post-admission mortality rate for all specialities), $Y$ is a vector of patient characteristics (age, gender, number of comorbidities, number of operations during CIS, transferred to institution dummy, and healthcare resource group [HRG]/diagnosis related group [DRG] dummy), and $\varepsilon$ is the idiosyncratic error term.

\section{Dependent Variables}


Three relevant outcome variables were identified based on the European Core Health Indicators and the OECD Healthcare Quality Index. The first outcome relates to the extent of healthcare use, this is the length of a CIS. This outcome is measured for the breast cancer and STEMI patients. The second outcome variable relates to the quality of the care delivered. This process outcome is 28-day emergency readmission post-discharge, measured for STEMI patients only due to insufficient occurrences within the breast cancer sample. The final outcome analysed is a health outcome captured by 30 -day survival post-admission. Again, this outcome is measured for STEMI patients only.

\section{Independent Variables}

The main independent variable of interest, the MORNI, is estimated in three steps using the questionnaire data obtained from participating hospitals in each of the countries involved in the MUNROS project.

The MORNI is a measure of skill mix estimated at the hospital level. MORNI estimation was conducted using all hospitals from all nine countries involved in the MUNROS project (Gibson and Sutton, 2019). Our analysis applies the MORNI estimates from Gibson and Sutton (2019) for the subset of countries with accessible administrative data. The first step is to estimate a logit model for the physician category. The purpose of the logit model is to generate an odds ratio for physicians completing a task at a specific hospital after controlling for other relevant factors which may influence the input of a staff member (age, gender, years in the role, and hours per week spent on the pathway). A dummy variable was formed for each task component to indicate if the staff member was involved in completion of this task. The model was then estimated for all task components simultaneously. This process implies that all tasks have equal weight and the contribution of staff is not relative. Hospital dummies are included in the model to provide the relevant odd ratios. Country dummies are also included to provide a national average odds ratio. The second step to generate the MORNI is to repeat this process for respondents who are categorised as a nurse. The MORNI is formed in the third step by taking the ratio of the two odds ratios. Specifically, the MORNI for hospital $h$ and care pathway $p$ is defined as:

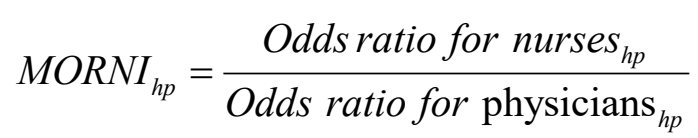


The MORNI measures the relative odds that a task along the care pathway will be undertaken by a nurse. Larger values indicate greater nurse involvement in treatment, relative to physicians, along the care pathway. The advantage of this measure is that it captures how skills combine to complete tasks on a pathway, rather than simply concentrating on the absolute magnitudes of nurses and physicians. Therefore, within our analysis, the measure will indicate combination of allocated resources required to achieve patient outcomes on a pathway.

The MORNI is not a ratio of the number of doctors and nurses. If an over or under supply of one category of staff exists, this would only affect the MORNI if the pattern of tasks completed by the staff groups was altered. For example, if an oversupply of doctors led to doctors performing task components elsewhere performed by nurses.

In cases where the response rate prevented estimation of an odds ratio for one category of staff, the national average was used as the best available estimate. National averages are only used for either nurses or physicians, never both. Such estimates were necessary more often for physicians on the STEMI pathway. This imputation ensured that data was not discarded when it was possible to estimate one component of the MORNI and was essential given the data constraints when estimating our model. The national averages result from the same model as the hospital-level estimates from Gibson and Sutton (2019) using the same task-level data.

Within our model (1) additional hospital-level variables are used to control for characteristics of the location for treatment which may impact on the production of patient outcomes. A binary variable is included to indicate if the location for treatment was a teaching hospital. The median waiting time for elective treatment for all specialities combined is included to capture the extent of excess demand for treatment at each hospital. A measure of overall hospital quality is provided by the 30-day post-admission mortality rate aggregated across all pathways available at the hospital, not just those included in our analysis.

To control for patient heterogeneity, we include four age categories, gender (for STEMI only, the breast cancer sample is restricted to females), and a variable indicating that the patient was transferred to an institution on discharge (care homes, psychiatric hospitals, and prisons), which may cause a delayed transfer of care.

A further three variables are included to capture the varying complexity of inpatient cases. A categorical variable captures the number of comorbidities which a patient has. A second variable captures the number of surgical procedures conducted throughout a CIS. The final variable accounting for casemix heterogeneity across hospitals is the HRG/DRG assigned to the longest episode within a CIS. Dummy variables for each HRG/DRG code are included 
to account for non-linearity in this variable. As our sample is pathway specific, sample members are assigned to a narrow range of $\mathrm{HRG} / \mathrm{DRG}$ codes relevant to the care pathway.

\section{Results}

Table 1 and Table 2 provide descriptive statistics for the breast cancer and STEMI samples, respectively. In all countries we observe variation in outcomes between pathways. On average, a CIS on the STEMI pathway is longer than for breast cancer.

We also observe variation between countries within a pathway. Although the tail of the STEMI CIS distribution is long in all countries, this is much more the case in Scotland and England. On the breast cancer pathway, the shortest mean CIS is in England, which also has the lowest variance in this outcome. On the STEMI care pathway $4.2 \%$ of the Scottish sample does not survive beyond 30 days following admission to hospital, the equivalent figure in Norway is $5.5 \%$ and in England the figure is highest at $7.5 \%$. The rate of emergency readmissions within 28 days is at least four times higher in Scotland and England relative to Norway.

Variation in the organisation of care can be observed at many levels. Within a country and pathway, the standard deviations show that there is substantial variation in the composition of the workforce involved in delivering the same task components on the care pathway. We also observe variation between pathways within country, and between countries within a pathway. The mean value of the MORNI on the breast cancer pathway is greater than 1.5 in all three countries, indicating that the relative involvement of nurses is higher than that of physicians. For STEMI the equivalent figure is slightly higher than 1 in Scotland and England and below 1 in Norway.

\section{Regression results}

Table 3 provides the results of the ZTNB regression of the MORNI (plus controls) on the length of a CIS. We observe differing associations within country between pathways, and between countries within pathways.

Increasing relative nurse involvement in treatment is associated with shorter inpatient stays on both care pathways in Scotland, but only the STEMI pathway in Norway and England. In terms of magnitude, a change from an even chance of being treated by a nurse or a physician $(\mathrm{MORNI}=1)$, to being twice as likely to be treated by a nurse $(\mathrm{MORNI}=2)$ would reduce the incidence of staying a further day by approximately $36.1 \%$ on the breast cancer pathway in 
Scotland, all other things being constant. The equivalent rate for STEMI is a $23.7 \%$ reduction in Scotland, 24.1\% in Norway and 3.1\% in England.

The results from the probit regressions (Table 4) indicate that the process outcomes can be improved by task substitution on the STEMI pathway. A one unit increase in the MORNI is associated with a 5.8\% reduction in the emergency readmission rate in Scotland, but there is no statistically significant effect in Norway or England.

Both shorter inpatient stays and a lower rate of emergency readmission are desirable outcomes for patients and health systems. However, there is some indication in Table 5 that higher levels of relative nurse involvement may have an adverse effect on health outcomes on the STEMI pathway in Scotland. Although within the full sample there is no statistically significant effect of the MORNI on 30-day survival probability, the coefficient does have a negative sign and a substantial section of the confidence interval is negative 95\% CI [-0.035, 0.013]. Therefore, for STEMI patients in Scotland, we fail to reject the possibility that greater relative nurse involvement in treatment may reduce their 30-day survival probability. This result is observed to a lesser degree in the Norwegian and English samples.

\section{Discussion}

This paper used a unique combination of primary data linked to high quality administrative data to investigate the effect of variation in the composition of the healthcare workforce on specific patient outcomes. The Measure of Relative Nurse Involvement (MORNI) was employed to capture variation in nurse involvement, relative to physicians, in tasks along the care pathways for breast cancer and STEMI. The results of the regression analysis illustrate that patient outcomes are influenced by varying the labour inputs to production, although the impact varies between the care pathways and possibly health systems.

When interpreting the results, we refer to a one unit change in the MORNI. Such a change would represent a substantial shift in workforce planning models. However, the mean levels of the MORNI in Tables 1 and 2 show substantial within-pathway variation in skill mix, both between countries and between hospitals. This variation indicates a range in observed values for the MORNI larger than the one unit change which the interpretation of the regression coefficients refer to. Therefore, due to existing differences in the composition of teams delivering care, two identical individuals undergoing the same treatment, from physicians and nurses of identical quality, on the breast cancer pathway in Scotland are predicted to spend substantially different lengths of time in hospital given our observed values of the MORNI. 
The intuition for this finding is that delays in delivering treatment are reduced as nurses complete a larger proportion of the relatively routine tasks on a care pathway. Examples of such tasks identified, using the MUNROS questionnaire data, by Maier et al. (2018) include prescribing therapy for cancer-related fatigue, and revising chemotherapy. The results suggest a positive impact when changes in workforce planning models incorporate task substitution. That we do not observe this result in Norway and England, suggests that these countries have already maximised the benefits of task substitution on the breast cancer pathway. This optimal level of skill mix would be between the 2.648 average observed in Norway and 2.378 observed in England, which is substantially above the 1.614 observed on average in Scotland.

On the STEMI pathway our results predict that there is still scope for substitution to achieve shorter inpatient stays in Scotland, Norway, and England. The greatest reductions are predicted in Norway, which currently has the lowest mean level of the MORNI at 0.859. The predicted reductions are smallest in England and only statistically significant at the $10 \%$ level. Therefore, the maximum scope for substitution on the STEMI pathway may be at a MORNI close to the value observed in England (1.352). Examples of tasks components on the STEMI pathway where nurses have expanded roles in some countries include managing vascular comorbidities, and conducting assessments of which protocols to apply (Maier et al., 2018).

It is assumed that patients will value shorter inpatient stays, provided clinical outcomes are achieved. At the same time, shorter inpatient stays should help to constrain the per patient treatment cost. Levels of substitution less substantial than a one unit change in the MORNI would reduce the length of inpatient stays and quickly accumulate in terms of total hospital days saved on a care pathway. Therefore, increasing relative nurse involvement in tasks may reduce excess demand for care by contributing to budget savings. Within the breast cancer pathway in Scotland, our results show there is scope for substitution without adversely affecting patient outcomes. On the STEMI pathway the predictions are more complex, since outcomes other than the length of an inpatient stay are also associated with variation of labour inputs to production.

In addition to shorter inpatient stays, the results also suggest that increasing the relative involvement of nurses in treatment has either a positive (lower) or no effect on the rate of emergency readmissions within 28 days for the STEMI pathway. Lower or unchanged levels of emergency readmissions should also help to constrain costs per patient. For STEMI, the association identified suggests that process outcomes are being achieved despite shorter inpatient stays. This result shows some consistency with Martin et al. (2016) which found shorter length of stay was not associated with readmission rates for hip replacement and hernia, 
but stroke patients with shorter length of stay were more likely to be readmitted. Evidence of heterogeneity across care pathways illustrates the importance of analysing outcomes at this level of disaggregation.

For other aspects of care quality there is some evidence that efficiency gains may have adverse effects on outcomes in terms of a reduced 30-day survival probability on the STEMI pathway. Such an effect is consistent with the literature summarised in Section 1, which showed that reductions in skill mix were associated with increased rates of adverse outcomes across a range of settings. It may be expected that lowering the quality of inputs to production would result in a lower quality output. For some task components this difference will be insignificant, but on the STEMI pathway in Scotland some of the substitution may be inappropriate. Further research will be required to identify the task components which have the greatest scope for substitution without an adverse effect on patient outcomes. Likewise, a full evaluation of the costs of increased adverse outcomes against the efficiency benefits of changes in skill mix would also be a useful route for further research.

This paper represents the first analysis of the relationship between skill mix and patient outcomes which focuses on variation of inputs to task components on specific care pathways. We have demonstrated the usefulness of constructing a task-component focused measure of skill mix, the MORNI (Gibson and Sutton, 2019), for analysing changes in workforce composition in the delivery of healthcare. Although this research focuses on nurses, with enough data the MORNI may be disaggregated to finer levels of health professionals. For example, allowing a distinction in the skill levels within nurses. However, a limitation of the MORNI is that collection of sufficient data is resource intensive. This would be partially overcome as researchers and health professionals become more familiar with the process.

The most evident limitation is that the data relates to a single year and that it covers only a small number of hospitals. Repeated observations across time would enable analysis of changes to workforce composition and care delivery within individual hospitals. This would provide an opportunity to move beyond the statements regarding associations which are presented here to generate models that address causality. Likewise, a greater volume of data may make it possible to identify the upper limit of nurse involvement on pathways, although comparison of the results from parallel models give some indication.

It is prudent to consider further factors which may have influenced the results. Firstly, the response rate could affect the MORNI if a relationship exists between the number of tasks completed by a staff member and the likelihood of completing the questionnaire. Secondly, there may be variation in adherence to treatment protocols across hospitals which may 
influence the results (Chung et al., 2015). We cannot entirely rule out either interpretation, although attempts were made to reduce treatment heterogeneity and limit to the influence of response rates. Future work could aim to ensure representativeness in the staff samples.

Further extensions could include increasing the range of health outcomes which are captured. Although 30-day survival post-admission is highly relevant to the STEMI pathway, health outcomes associated with breast cancer often involve longer time horizons - for example, 2- and 5-year survival rates. Additionally, patients may particularly value shorter waiting times for elective treatments, which may also be influenced by the MORNI. In this instance, our data did not allow us to observe these outcomes. Despite these limitations, our analysis has highlighted the importance of tailoring workforce planning models to specific care pathways if efficiency gains are to be achieved without an increase in adverse patient outcomes.

\section{Conclusion}

This paper has provided evidence that there is scope for substitution of task components between nurses and physicians. Our key finding is that the effects of such substitution, varying the skill mix, are pathway specific. Therefore, workforce planning models, and empirical analysis of the effect on outcomes, should be conducted at this level and be tailored specifically to care pathways. Patient outcomes should not be assumed to be constant when the labour inputs to production vary.

In addition to being pathway specific, our results could be interpreted as showing that the health system setting also influences the effect of skill mix on patient outcomes. However, our conjecture is that the effect of relative changes of nurse involvement in treatment is homogenous within pathway between countries, for some outcomes at least. This conjecture is based upon the relationship between the mean MORNI values and the regression coefficients within each country. This relationship is observed despite running parallel, rather than pooled, analysis. Further research is needed to test this conjecture, but if correct, this would indicate that the maximum MORNI to achieve efficiency gains is around 1.3 on the STEMI pathway and around 2.5 on the breast cancer pathway. In this respect there is greater scope for substitution between nurses and physicians on the breast cancer pathway compared to the STEMI care pathway, and these efficiency gains (shorter inpatient stays) can be achieved without an adverse impact on the effectiveness of treatment.

Although there is potential to improve aspects of care delivery through substitution of tasks from physicians to nurses, expanded professional roles are not a panacea. They are 
associated with both positive and adverse changes in patient outcomes. For STEMI, and possibly more generally across other care pathways, any evaluation of the changes resulting from variations in skill mix must consider the societal cost of excess mortality in addition to reductions in the cost per inpatient stay. 


\section{References}

Acemoglu, D. and D. Autor, Skills, Tasks and Technologies: Implications for Employment and Earnings, in Handbook of Labor Economics, ed. by O. Ashenfelter, and D. Card, vol. 4, Part B.: Elsevier (2011): 1043- 171.

Aiken, L. H., Sloane, D., Griffiths, P., Rafferty, A. M., Bruyneel, L., . . Sermeus, W. (2017). Nursing skill mix in European hospitals: cross-sectional study of the association with mortality, patient ratings, and quality of care. BMJ Quality \& Safety, 26(7), 559-568. doi:10.1136/bmjqs-2016-005567

Blegen, M. A., Goode, C. J., Spetz, J., Vaughn, T., \& Park, S. H. (2011). Nurse staffing effects on patient outcomes: safety-net and non-safety-net hospitals. Medical Care, 49(4), 406-414. doi:10.1097/MLR.0b013e318202e129

Bond C, Bruhn H, de Bont A, van Exel J, Busse R, Sutton M, Elliott, R., on behalf of the MUNROS team. (2016). The iMpact on practice, oUtcomes and costs of New roles for health pROfeSsionals: a study protocol for MUNROS. BMJ Open. 6(4):e010511. doi:10.1136/bmjopen-2015-010511

Busby, J., Purdy, S., \& Hollingworth, W. (2017). Calculating hospital length of stay using the Hospital Episode Statistics; a comparison of methodologies. BMC Health Services Research, 17(1), 347-347. doi:10.1186/s12913-017-2295-z

Chung, S-C., Sundström, J., Galem, CP., James, S., Deanfield, J., Wallentin, L., Timmis, A., Jernberg, T., and Hemingway, H. (2015). Comparison of hospital variation in acute myocardial infarction care and outcome between Sweden and United Kingdom: population based cohort study using nationwide clinical registries. BMJ : British Medical Journal. 2015;351:h3913. doi: https://doi.org/10.1136/bmj.h3913

Dixon, J., Street A., Allwood D. (2018), Productivity in the NHS: why it matters and what to do next $B M J ; 363: \mathrm{k} 4301$

Estabrooks, C. A., Midodzi, W. K., Cummings, G. G., Ricker, K. L., \& Giovannetti, P. (2005). The impact of hospital nursing characteristics on 30-day mortality. Nursing Research, 54(2), 74-84.

Gibson, J., and Sutton, M., on behalf of the MUNROS team, (2019), Variations in the contribution of physicians and nurses to healthcare delivery: A comparison across nine European countries, MUNROS Work Package 5: Healthcare Professionals and Managers [Working paper available on request]

Griffiths P, Ball J, Drennan J, et al. (2014), The association between patient safety outcomes and nurse/healthcare assistant skill mix and staffing levels and factors that may influence staffing requirements (NICE evidence review). University of Southampton Centre for innovation and Leadership in Health Sciences.

Griffiths, P., Ball, J., Drennan, J., Dall'Ora, C., Jones, J., Maruotti, A., . . Simon, M. (2016). Nurse staffing and patient outcomes: Strengths and limitations of the evidence to inform policy and practice. International Journal of Nursing Studies, 63, 213-225. doi:10.1016/j.ijnurstu.2016.03.012

Griffiths P, Maruotti A, Recio Saucedo A On behalf of Missed Care Study Group, et al, (2019), Nurse staffing, nursing assistants and hospital mortality: retrospective longitudinal cohort study. BMJ Quality \& Safety, 28:609-617.

Hernandez, P., Dräger, S., Evans, D. B., Tan-Torres Edejer, T., \& Dal Poz, M. R. (2006). Measuring expenditure for the health workforce: evidence and challenges. Geneva: World Health Organization

Koch, M. (2016), Skills, Tasks and the Scarcity of Talent in a Global Economy. Review of International Economics, 24: 536-563. doi:10.1111/roie.12222 
Köppen, J., Maier, C. B., Busse, R., Bond, C., . . . Güldem Ökem, Z. (2018). What are the motivating and hindering factors for health professionals to undertake new roles in hospitals? A study among physicians, nurses and managers looking at breast cancer and acute myocardial infarction care in nine countries. Health Policy, 122(10), 1118-1125. doi:https://doi.org/10.1016/j.healthpol.2018.07.018

Kosecoff J, Kahn KL, Rogers WH, et al. (1990). Prospective Payment System and Impairment at Discharge: The 'Quicker-and-Sicker' Story Revisited. JAMA. 264(15). doi:10.1001/jama.1990.03450150080035

Maier, C. B., Köppen, J., Busse, R., \& MUNROS team. (2018). Task shifting between physicians and nurses in acute care hospitals: cross-sectional study in nine countries. Human Resources for Health, 16(1), 24. doi:10.1186/s12960-018-0285-9

Martin S, Street A, Han L, \& Hutton J. (2015). Have hospital readmissions increased in the face of reductions in length of stay? Evidence from England. Health Policy, 2016 120(1): 89-99 doi:10.1016/j.healthpol.2015.11.003

Needleman, J., Buerhaus, P., Mattke, S., Stewart, M., \& Zelevinsky, K. (2002). Nurse-Staffing Levels and the Quality of Care in Hospitals. New England Journal of Medicine, 346(22), 1715-1722. doi:10.1056/NEJMsa012247

Scottish Government, (2016), A National Clinical Strategy for Scotland, http://www.gov.scot/Resource/0049/00494144.pdf [accessed on 29 November 2018]

Street A, Gutacker N, Bojke C, Devlin N, Daidone S., (2014) Variations in outcome and costs among NHS providers for common surgical procedures: econometric analyses of routinely collected data. Health Services Delivery and Research, 2(1) DOI: 10.3310/hsdr02010

Tourangeau, A. E., Cranley, L. A., \& Jeffs, L. (2006). Impact of nursing on hospital patient mortality: a focused review and related policy implications. Quality \& safety in health care, 15(1), 4-8. doi:10.1136/qshc.2005.014514

Weiss, M. E., Yakusheva, O. and Bobay, K. L., (2011). Quality and cost analysis of nurse staffing,discharge preparation, and postdischarge utilization. Health Services Research, 46, 1473-1494. 
Table 1 Descriptive statistics for breast cancer samples

\begin{tabular}{|c|c|c|c|}
\hline & $\begin{array}{l}\text { Scotland } \\
(\mathrm{n}=961)\end{array}$ & $\begin{array}{l}\text { Norway } \\
(\mathrm{n}=1056)\end{array}$ & $\begin{array}{l}\text { England } \\
(\mathrm{n}=1286)\end{array}$ \\
\hline \multirow[t]{3}{*}{ Length of CIS (days) } & 3.123 & 3.662 & 1.916 \\
\hline & $(2.343)$ & $(4.267)$ & $(1.922)$ \\
\hline & {$[1-17]$} & {$[1-58]$} & {$[1-21]$} \\
\hline \multirow[t]{3}{*}{ MORNI } & 1.614 & 2.648 & 2.378 \\
\hline & $(0.553)$ & $(1.960)$ & $(1.642)$ \\
\hline & {$[0.606-2.302]$} & {$[0.936-7.239]$} & {$[0.871-6.053]$} \\
\hline \multirow[t]{2}{*}{ Teaching hospital } & 0.707 & 0.791 & 0.736 \\
\hline & $(0.456)$ & $(0.407)$ & $(0.441)$ \\
\hline \multirow{3}{*}{$\begin{array}{l}\text { 30-day all-cause mortality } \\
\text { rate }\end{array}$} & 2.777 & 5.130 & 3.337 \\
\hline & $(0.328)$ & $(0.381)$ & $(0.402)$ \\
\hline & {$[2.081-3.163]$} & {$[4.700-5.800]$} & [2.919-4.249] \\
\hline \multirow[t]{3}{*}{ Average waiting time (days) } & 37.896 & 72.854 & 29.495 \\
\hline & $(7.157)$ & $(10.226)$ & $(5.549)$ \\
\hline & {$[25-48]$} & {$[51-92]$} & {$[21-40]$} \\
\hline \multirow[t]{2}{*}{ age $<=45$} & 0.107 & 0.130 & 0.110 \\
\hline & $(0.310)$ & $(0.336)$ & $(0.314)$ \\
\hline \multirow[t]{2}{*}{ age $>45 \&$ age $<=65$} & 0.505 & 0.465 & 0.465 \\
\hline & $(0.500)$ & $(0.499)$ & $(0.499)$ \\
\hline \multirow{2}{*}{ age $>65$ \& age $<=79$} & 0.305 & 0.282 & 0.302 \\
\hline & $(0.461)$ & $(0.450)$ & $(0.460)$ \\
\hline \multirow[t]{2}{*}{ age $>79$} & 0.083 & 0.123 & 0.122 \\
\hline & $(0.276)$ & $(0.329)$ & $(0.328)$ \\
\hline \multirow[t]{2}{*}{ Comorbidities: 2 or less } & 0.851 & 0.596 & 0.467 \\
\hline & $(0.356)$ & $(0.491)$ & $(0.499)$ \\
\hline \multirow[t]{2}{*}{ Comorbidities: 3} & 0.081 & 0.182 & 0.149 \\
\hline & $(0.273)$ & $(0.386)$ & $(0.357)$ \\
\hline \multirow[t]{2}{*}{ Comorbidities: 4} & 0.043 & 0.112 & 0.118 \\
\hline & $(0.202)$ & $(0.315)$ & $(0.323)$ \\
\hline \multirow[t]{2}{*}{ Comorbidities: 5 or more } & 0.025 & 0.111 & 0.265 \\
\hline & $(0.156)$ & $(0.314)$ & $(0.442)$ \\
\hline \multirow{3}{*}{$\begin{array}{l}\text { Number } \\
\text { procedures }\end{array}$} & 3.329 & 1.653 & 4.736 \\
\hline & $(1.245)$ & $(1.229)$ & $(1.681)$ \\
\hline & {$[0-8]$} & {$[0-8]$} & {$[0-12]$} \\
\hline \multirow[t]{2}{*}{ Transferred to institution } & 0.002 & 0.062 & 0.004 \\
\hline & $(0.046)$ & $(0.240)$ & $(0.062)$ \\
\hline
\end{tabular}

Notes: Sample mean and standard deviation (in parentheses) for all variables. Range (in square brackets) included for continuous variables only.

Male, emergency readmission within 28-days, and 30-day survival excluded from the table due to insufficient variation within the samples to include these variables within regressions. 
Table 2 Descriptive statistics for STEMI samples

\begin{tabular}{|c|c|c|c|}
\hline & $\begin{array}{l}\text { Scotland } \\
(\mathrm{n}=910)\end{array}$ & $\begin{array}{l}\text { Norway } \\
(\mathrm{n}=1,919)\end{array}$ & $\begin{array}{l}\text { England } \\
(\mathrm{n}=4,738)\end{array}$ \\
\hline \multirow[t]{3}{*}{ Length of CIS (days) } & 5.316 & 4.342 & 6.834 \\
\hline & $(6.604)$ & $(4.720)$ & $(7.530)$ \\
\hline & {$[1-106]$} & {$[1-64]$} & {$[1-99]$} \\
\hline \multirow{2}{*}{$\begin{array}{l}\text { Emergency readmission } \\
\text { within 28-days }\end{array}$} & 0.111 & 0.028 & 0.136 \\
\hline & $(0.314)$ & $(0.165)$ & $(0.342)$ \\
\hline \multirow[t]{2}{*}{ 30-day survival } & 0.958 & 0.945 & 0.925 \\
\hline & $(0.200)$ & $(0.229)$ & $(0.263)$ \\
\hline \multirow[t]{3}{*}{ MORNI } & 1.013 & 0.859 & 1.352 \\
\hline & $(0.391)$ & $(0.532)$ & $(1.193)$ \\
\hline & {$[0.300-1.668]$} & {$[0.294-1.755]$} & {$[0.293-3.473]$} \\
\hline \multirow[t]{2}{*}{ Teaching hospital } & 0.431 & 0.701 & 0.551 \\
\hline & $(0.495)$ & $(0.458)$ & $(0.497)$ \\
\hline \multirow{3}{*}{$\begin{array}{l}\text { 30-day all-cause mortality } \\
\text { rate }\end{array}$} & 2.787 & 5.383 & 3.483 \\
\hline & $(0.307)$ & $(0.723)$ & $(0.397)$ \\
\hline & {$[2.081-4.011]$} & {$[4.700-7.200]$} & [2.919-4.249] \\
\hline \multirow[t]{3}{*}{ Average waiting time (days) } & 34.140 & 69.810 & 31.845 \\
\hline & $(4.991)$ & $(13.233)$ & $(3.761)$ \\
\hline & {$[16-48]$} & {$[45-87]$} & {$[22-40]$} \\
\hline \multirow[t]{2}{*}{ age $<=45$} & 0.093 & 0.059 & 0.044 \\
\hline & $(0.291)$ & $(0.235)$ & $(0.205)$ \\
\hline \multirow[t]{2}{*}{ age $>45 \&$ age $<=65$} & 0.489 & 0.459 & 0.331 \\
\hline & $(0.500)$ & $(0.498)$ & $(0.471)$ \\
\hline \multirow[t]{2}{*}{ age $>65 \&$ age $<=79$} & 0.296 & 0.326 & 0.333 \\
\hline & $(0.457)$ & $(0.469)$ & $(0.471)$ \\
\hline \multirow[t]{2}{*}{ age $>79$} & 0.122 & 0.156 & 0.292 \\
\hline & $(0.327)$ & $(0.363)$ & $(0.455)$ \\
\hline \multirow[t]{2}{*}{ Male } & 0.731 & 0.731 & 0.630 \\
\hline & $(0.444)$ & $(0.444)$ & $(0.483)$ \\
\hline \multirow[t]{2}{*}{ Comorbidities: 2 or less } & 0.516 & 0.417 & 0.119 \\
\hline & $(0.500)$ & $(0.493)$ & $(0.324)$ \\
\hline \multirow[t]{2}{*}{ Comorbidities: 3} & 0.159 & 0.209 & 0.111 \\
\hline & $(0.366)$ & $(0.407)$ & $(0.314)$ \\
\hline \multirow[t]{2}{*}{ Comorbidities: 4} & 0.151 & 0.163 & 0.134 \\
\hline & $(0.358)$ & $(0.369)$ & $(0.340)$ \\
\hline \multirow[t]{2}{*}{ Comorbidities: 5 or more } & 0.174 & 0.211 & 0.637 \\
\hline & $(0.379)$ & $(0.408)$ & $(0.481)$ \\
\hline \multirow{3}{*}{$\begin{array}{l}\text { Number of } \quad \text { surgical } \\
\text { procedures }\end{array}$} & 2.122 & 0.978 & 1.801 \\
\hline & $(1.179)$ & $(1.083)$ & $(2.129)$ \\
\hline & {$[0-11]$} & {$[0-12]$} & {$[0-8]$} \\
\hline \multirow[t]{2}{*}{ Transferred to institution } & 0.044 & 0.320 & 0.346 \\
\hline & $(0.205)$ & $(0.467)$ & $(0.476)$ \\
\hline
\end{tabular}

Notes: Sample mean and standard deviation (in parentheses) for all variables. Range (in square brackets) included for continuous variables only. 


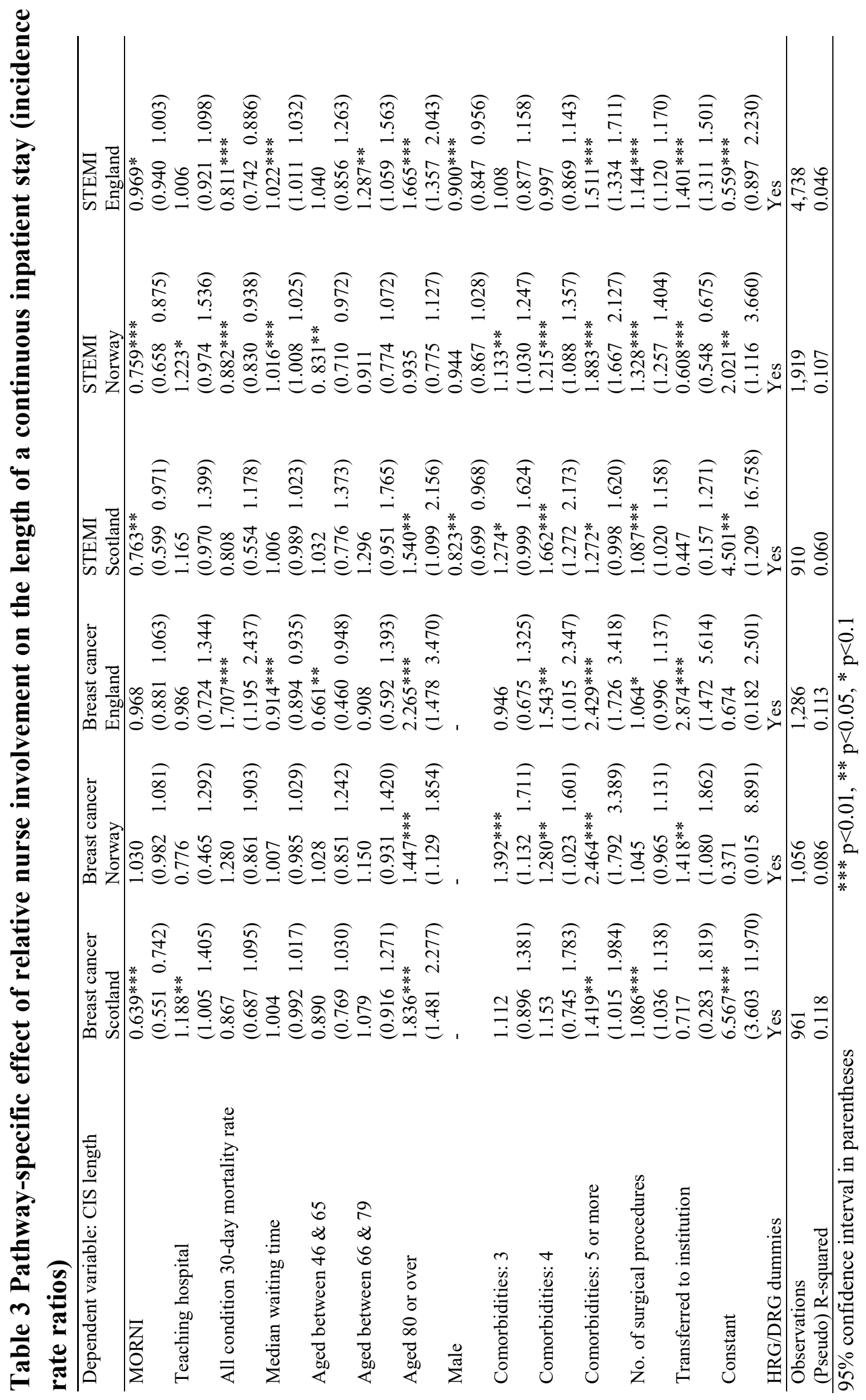




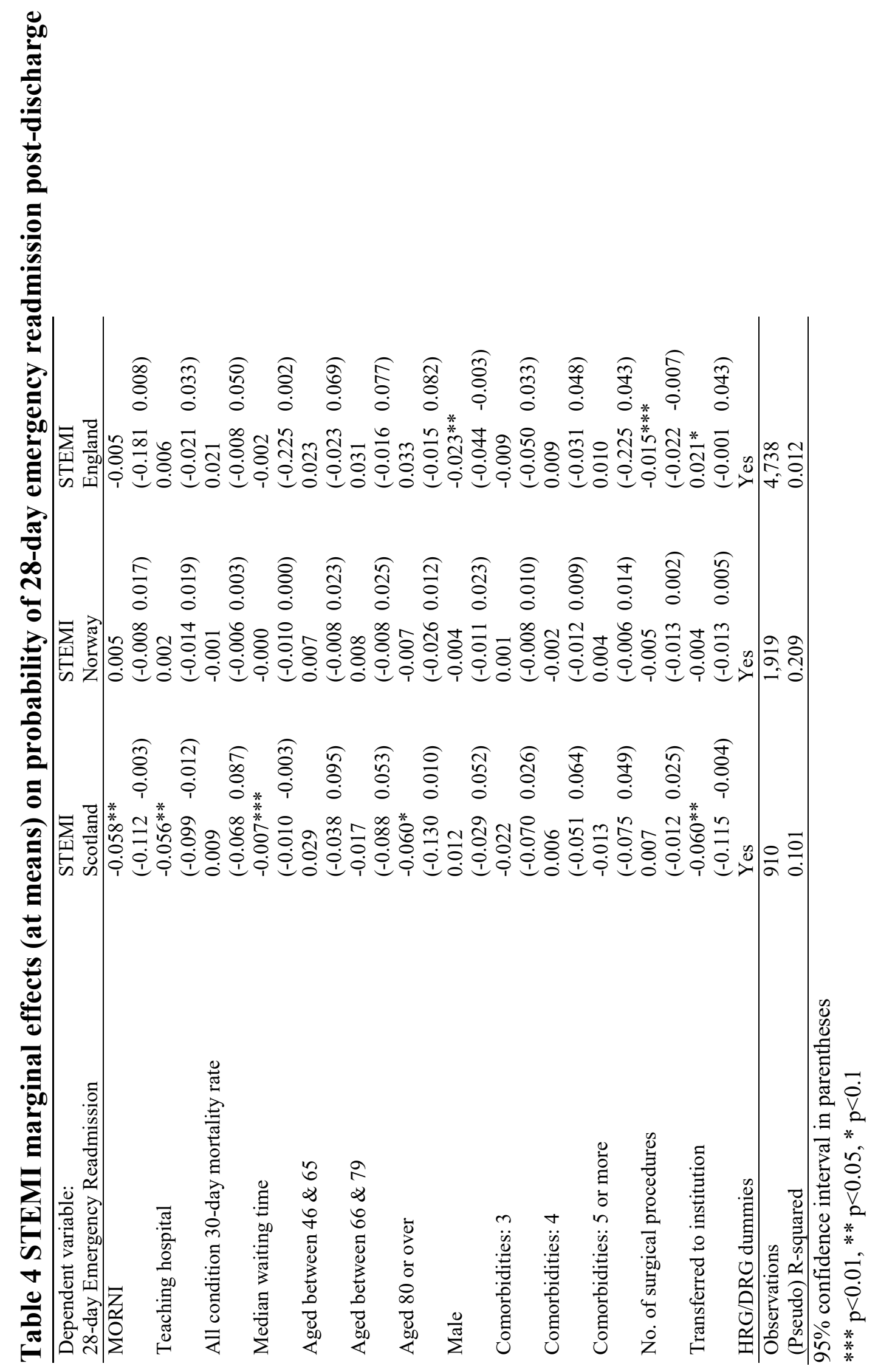




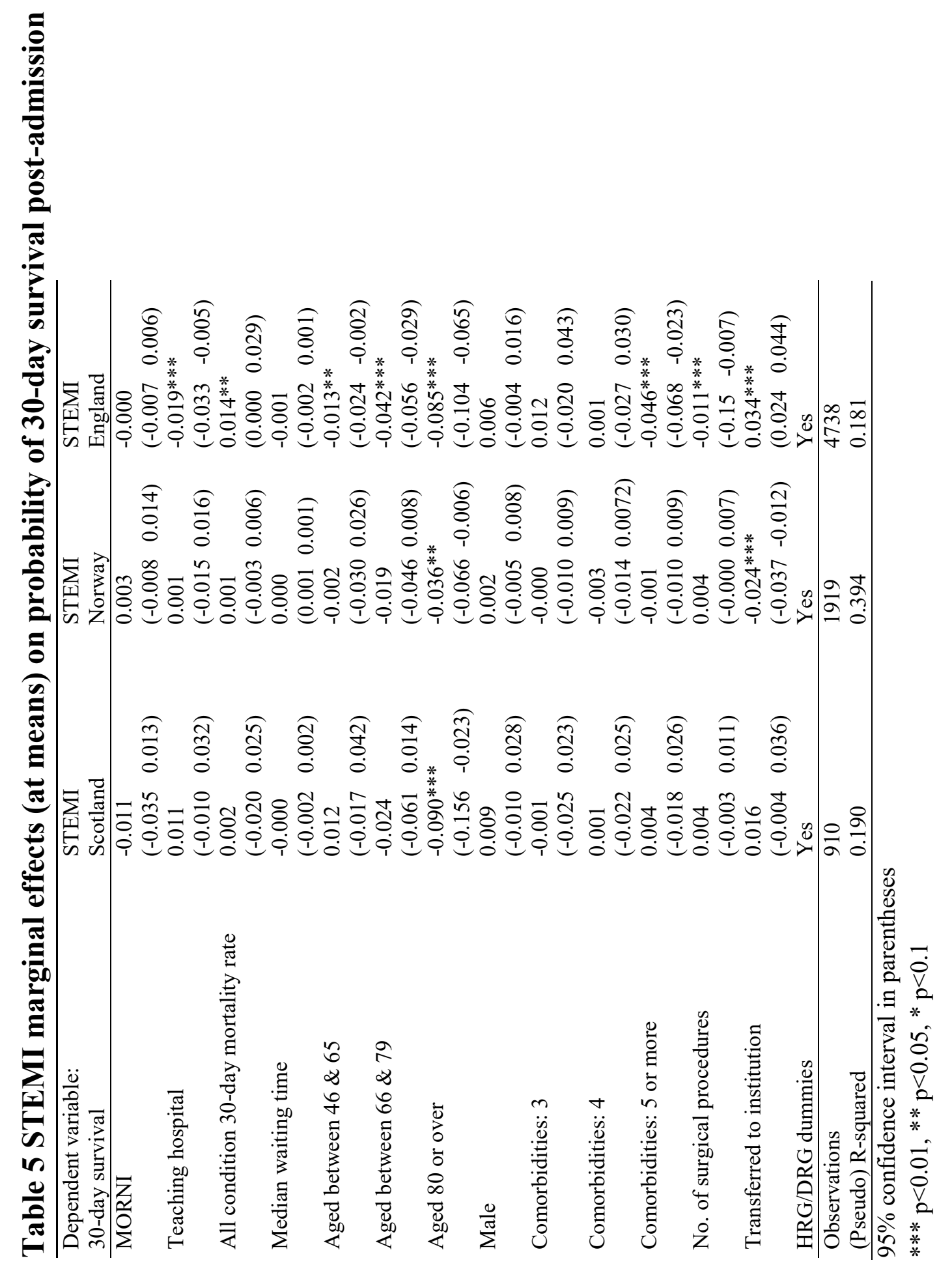


Study ID

\begin{tabular}{|l|l|l|l|l|l|l|l|l|l|l|l|l|l|}
\hline & - & & & - & & & & - & & & & - & \\
\hline
\end{tabular}

\section{Health Care Reform: the iMpact on} practice, oUtcomes and costs of New roles for health pROfeSsionals (MUNROS)

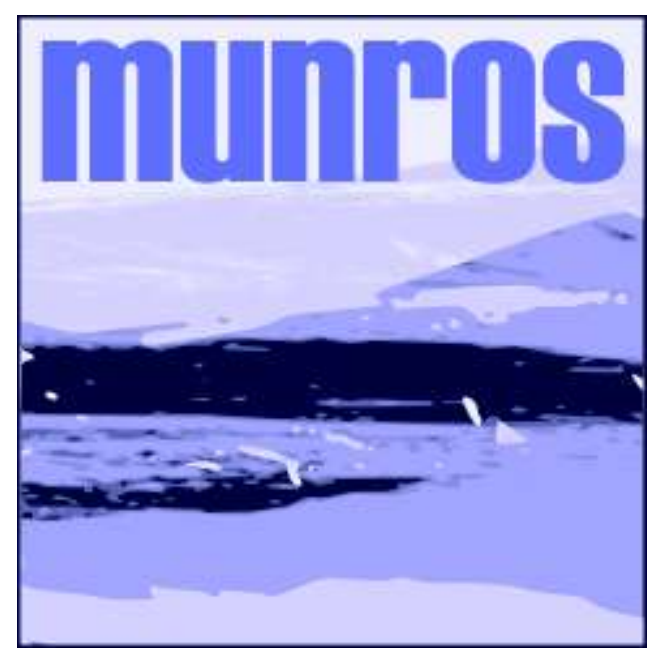

Health Care Professional Questionnaire (Breast Cancer)

All responses will be treated with complete confidence

Please try to complete the whole questionnaire even though some questions may appear similar 


\section{MUNROS Health Care Professional Questionnaire (Breast Cancer) \\ Task list question (Q17) only}




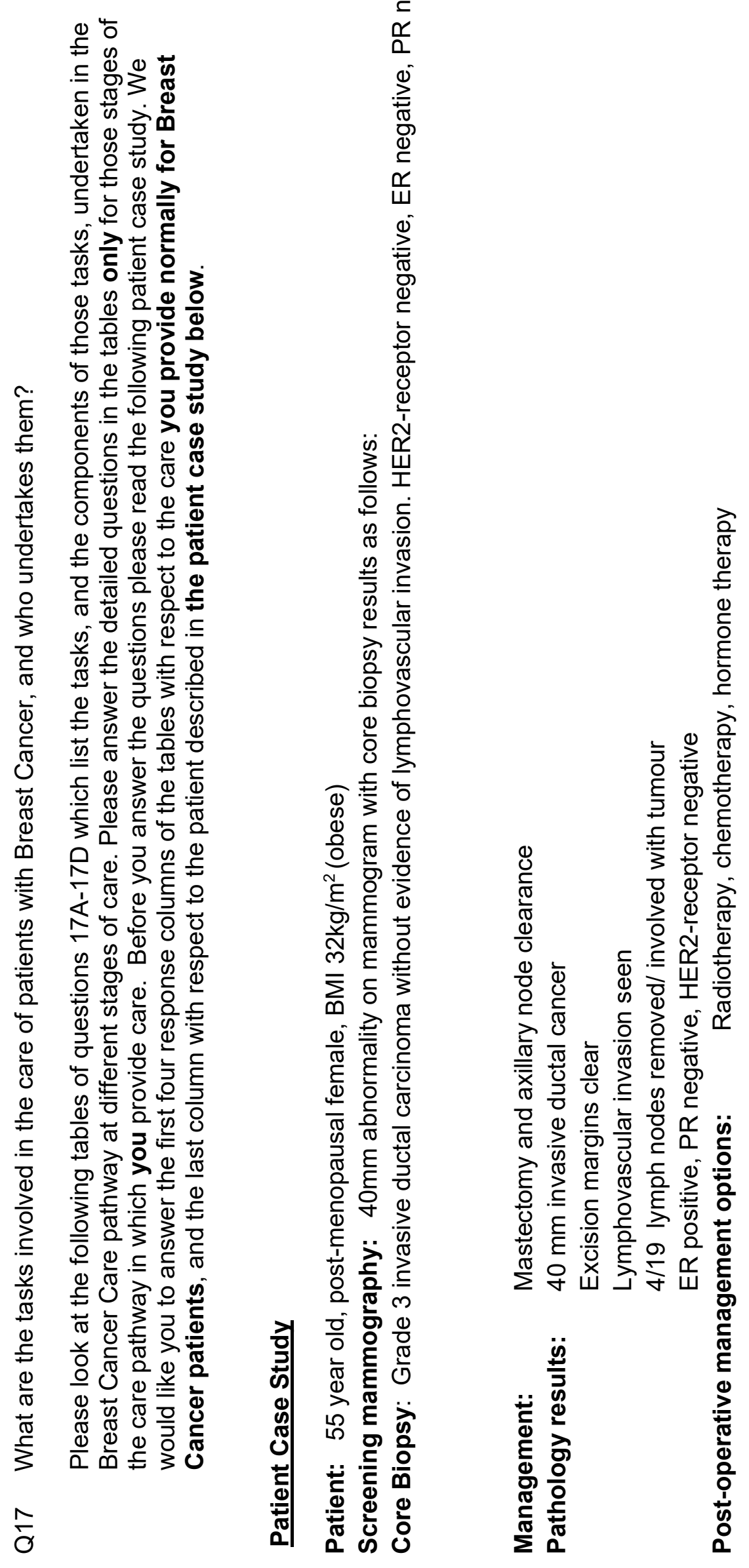




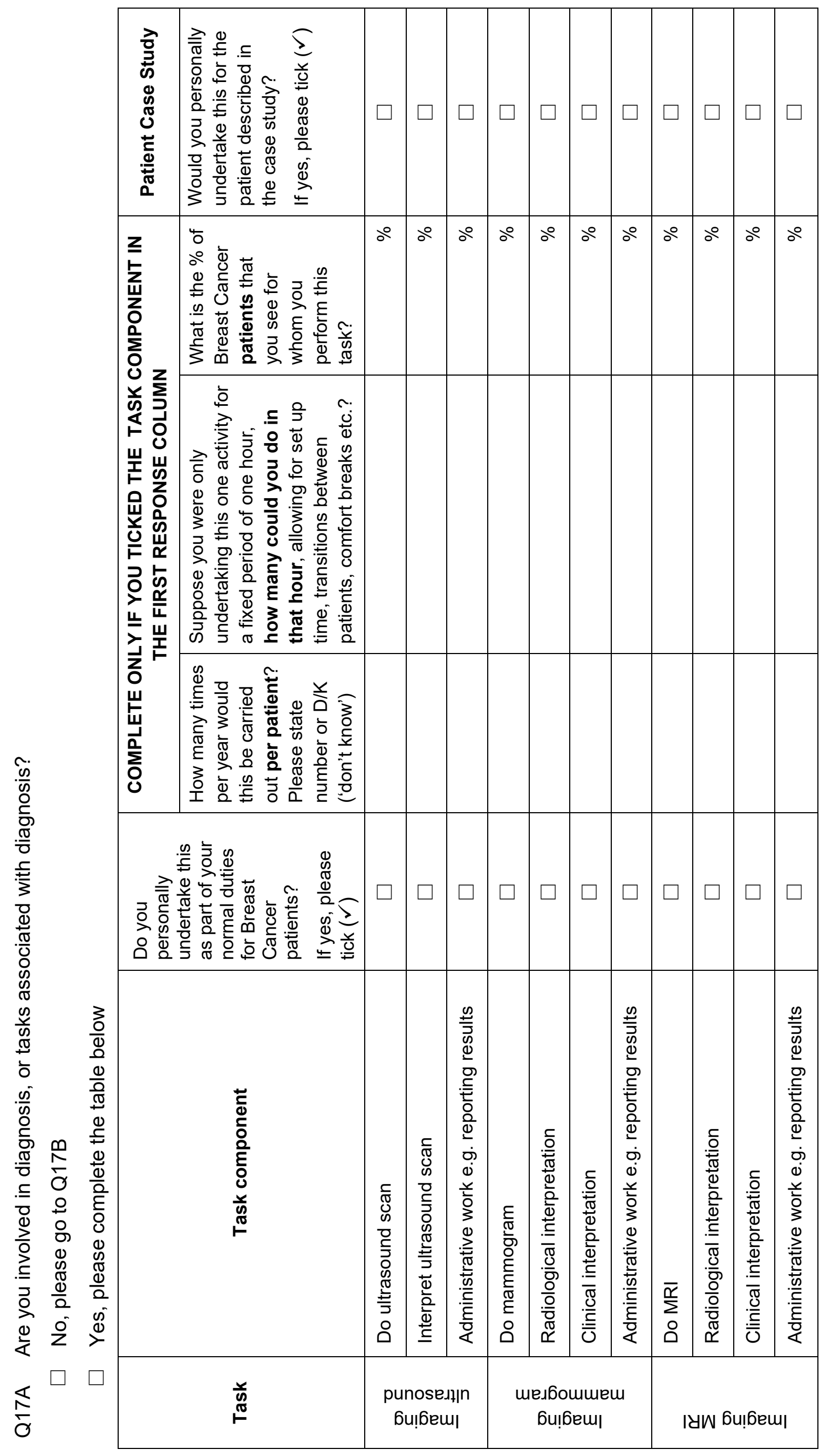

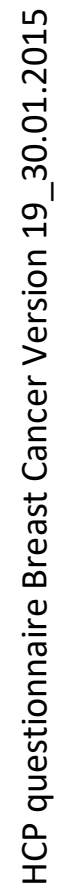




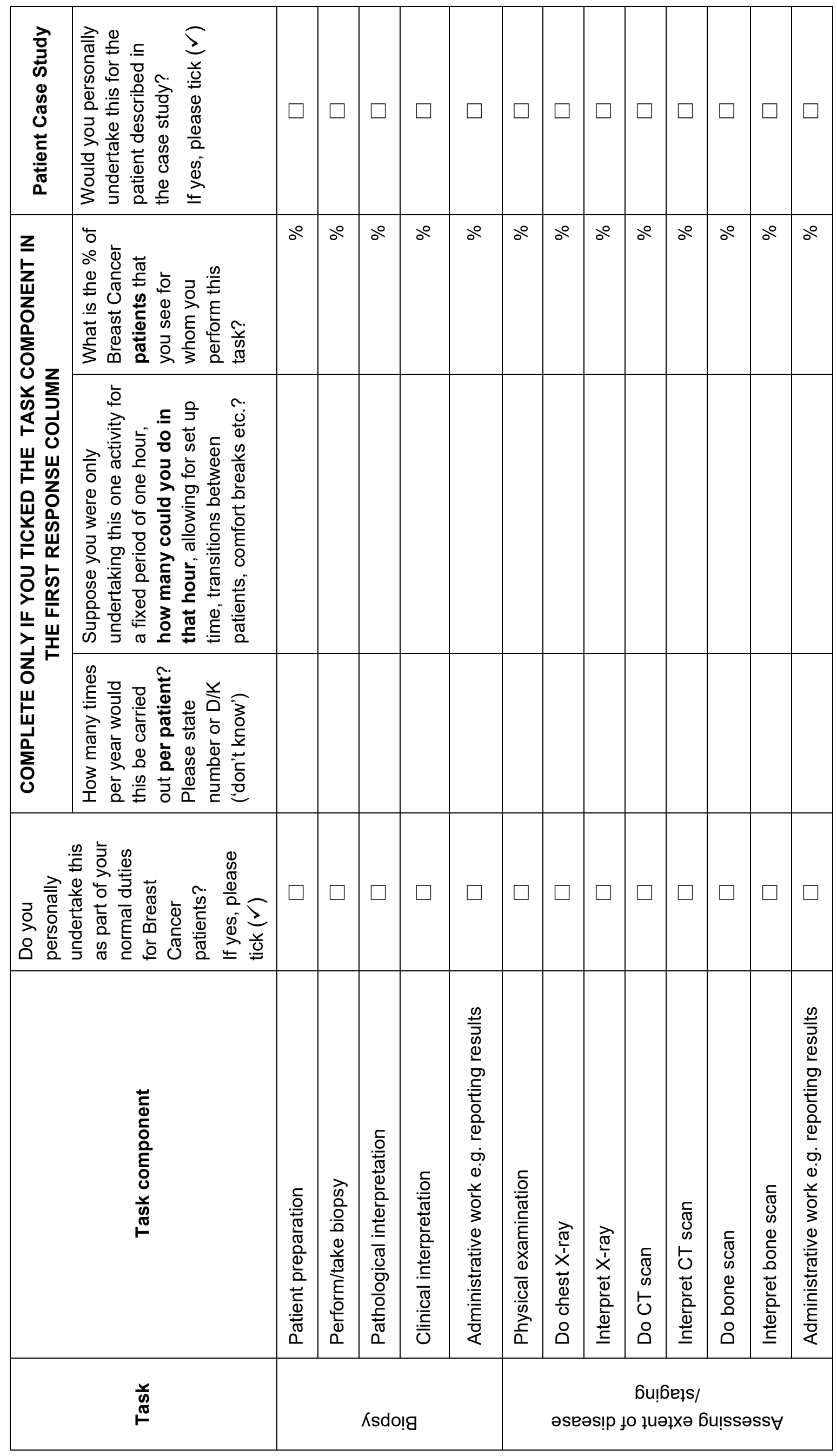

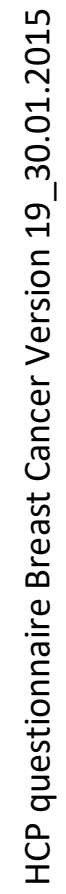




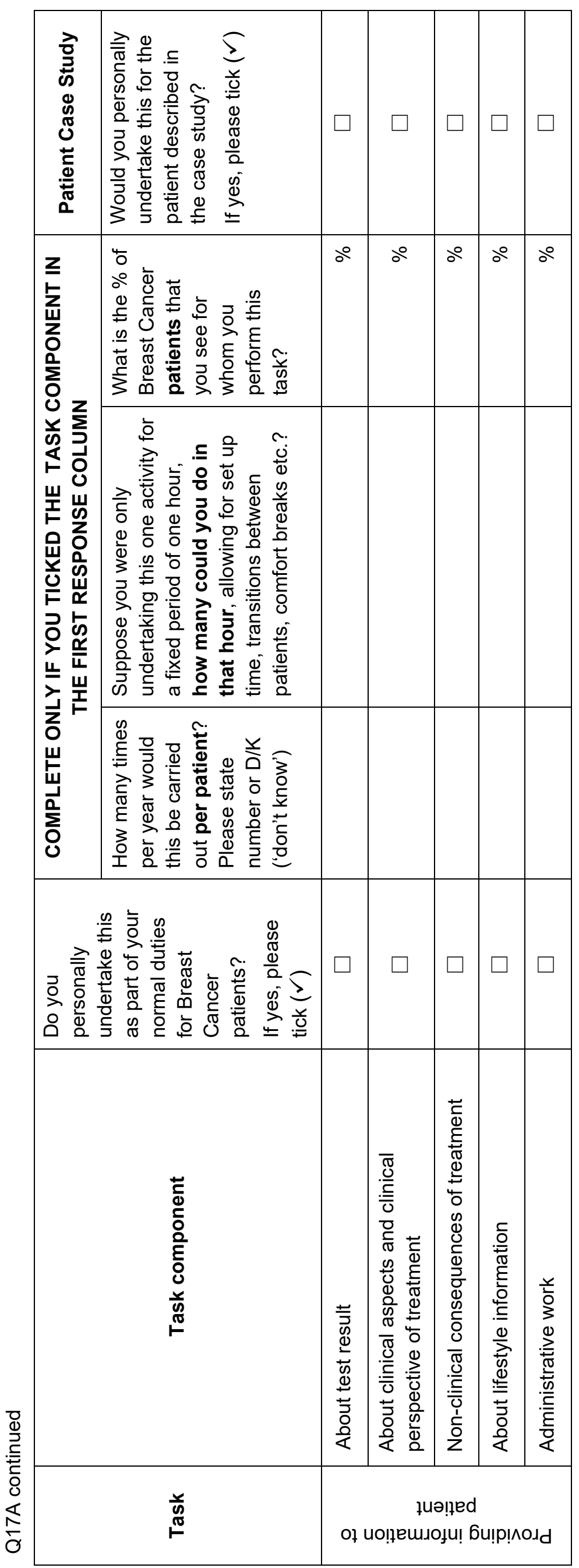




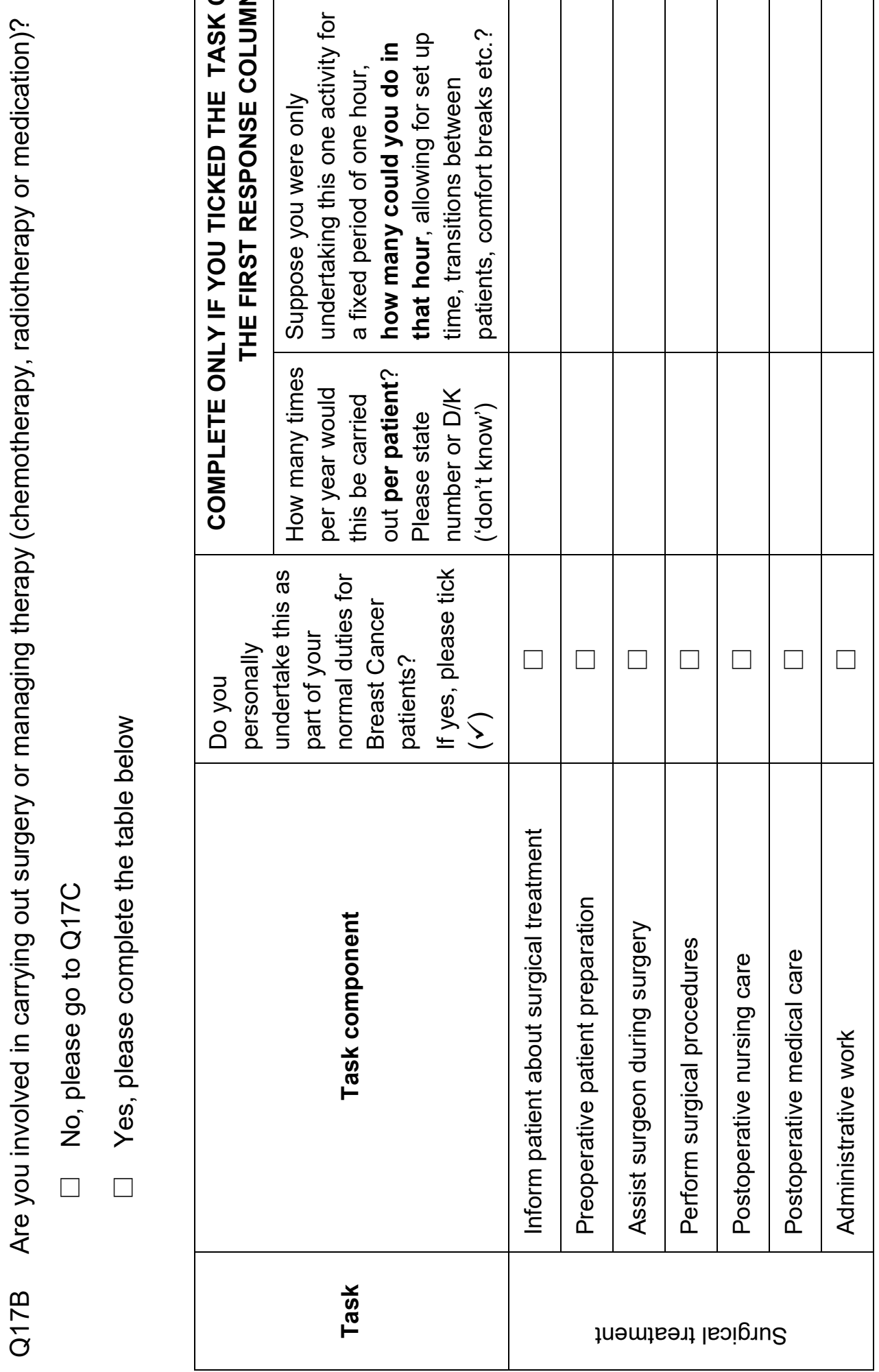




\begin{tabular}{|c|c|c|c|c|c|c|c|c|c|c|}
\hline 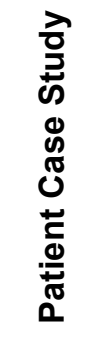 & 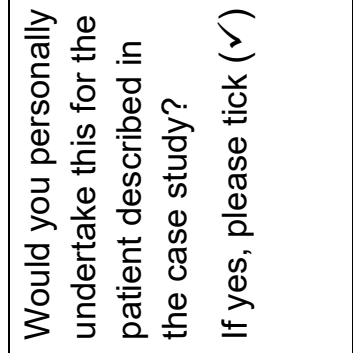 & $\square$ & $\square$ & $\square$ & $\square$ & $\square$ & $\square$ & $\square$ & $\square$ & $\square$ \\
\hline \multirow{3}{*}{ 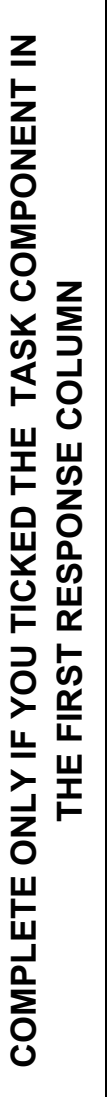 } & 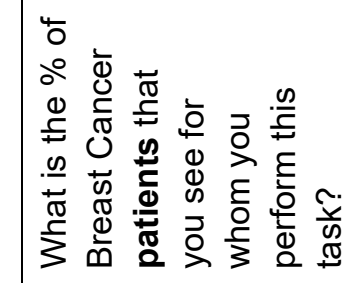 & $0^{0}$ & $0^{0}$ & ๙ & ๙0 & ๙ & ๙ & ๙ீ & $\partial^{\circ}$ & ๙ \\
\hline & 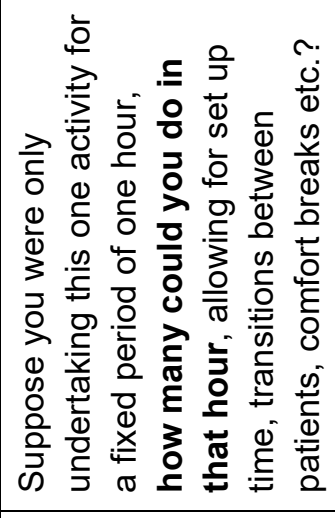 & & & & & & & & & \\
\hline & 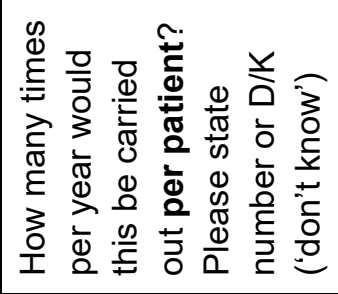 & & & & & & & & & \\
\hline \multicolumn{2}{|c|}{ 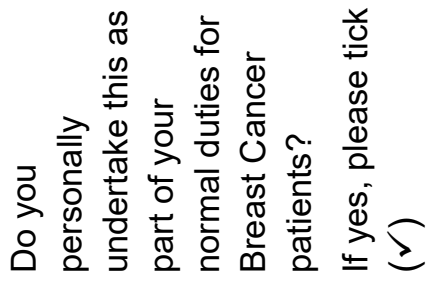 } & $\square$ & $\square$ & $\square$ & $\square$ & $\square$ & $\square$ & $\square$ & $\square$ & $\square$ \\
\hline \multicolumn{2}{|r|}{ 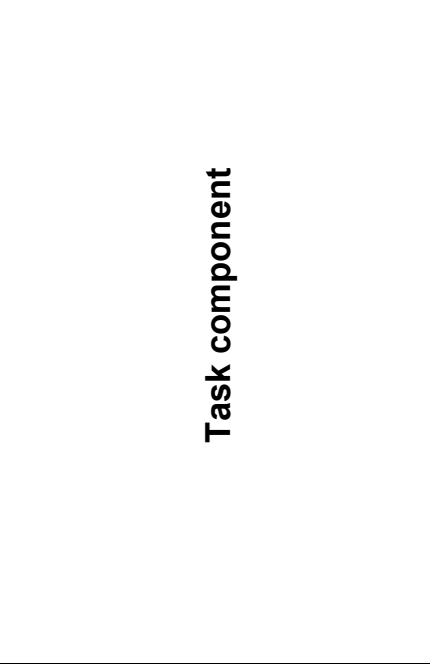 } & 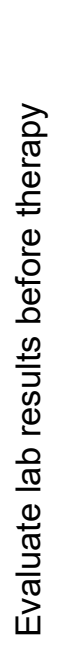 & 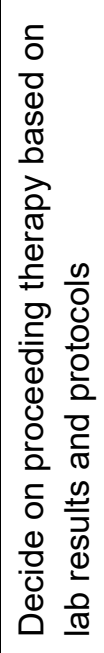 & 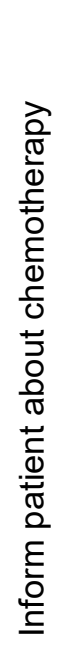 & 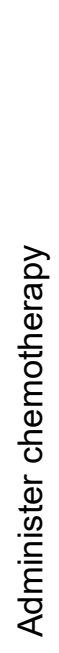 & 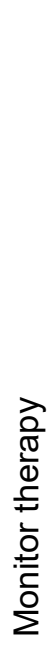 & 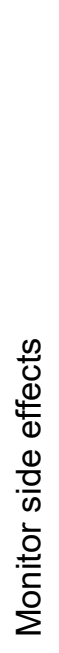 & 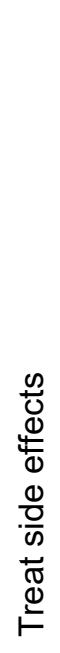 & 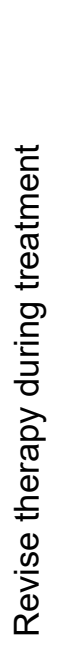 & 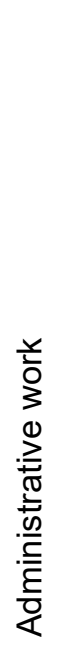 \\
\hline \multicolumn{2}{|r|}{ 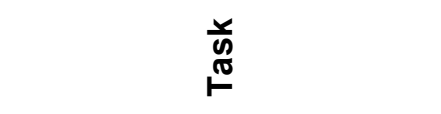 } & \multicolumn{9}{|c|}{ Кделәчұошәчว } \\
\hline
\end{tabular}




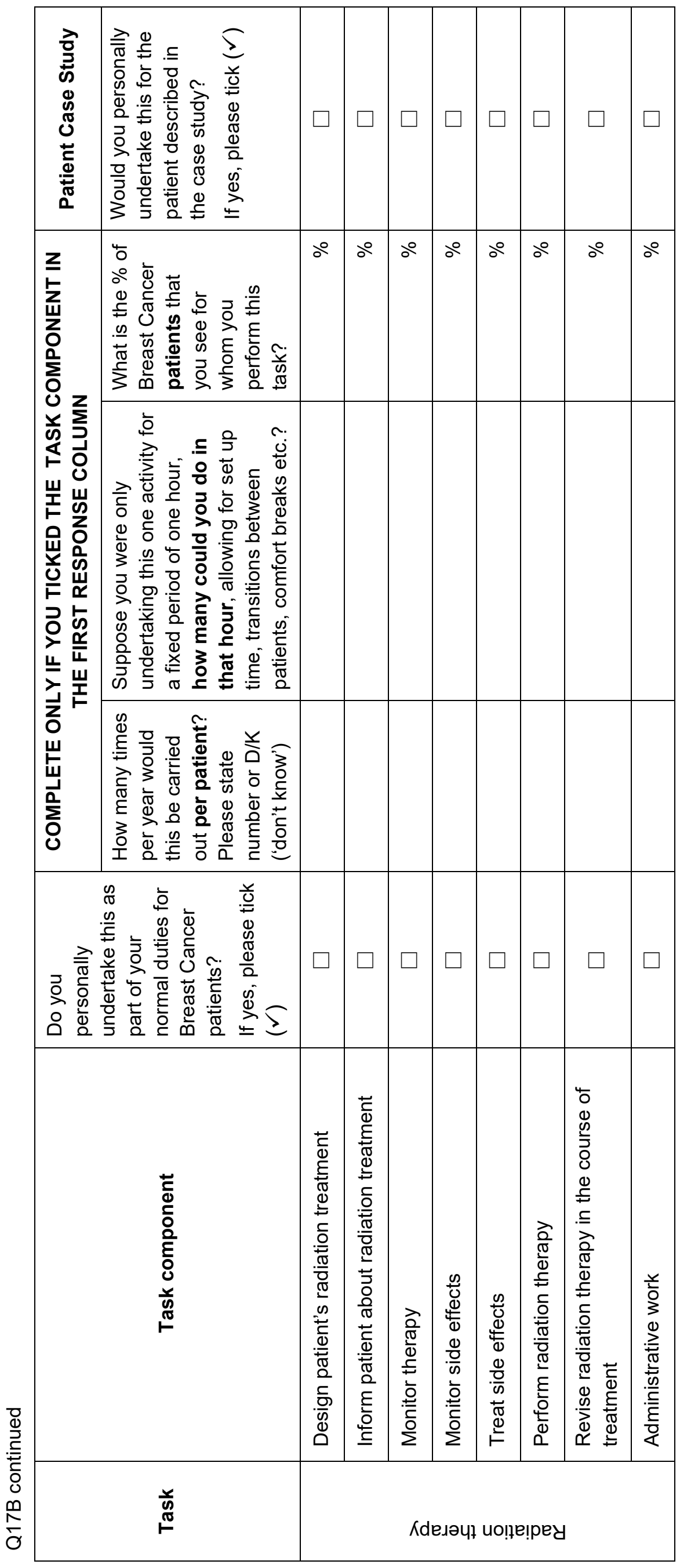




\begin{tabular}{|c|c|c|c|c|c|c|c|c|c|c|c|c|c|c|c|}
\hline 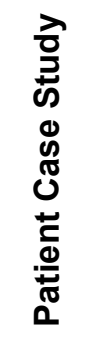 & 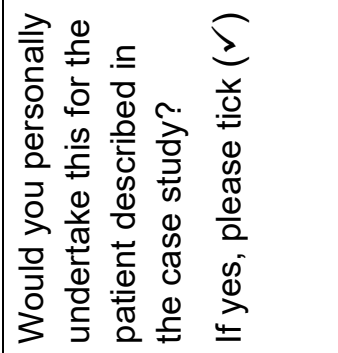 & $\square$ & $\square$ & $\square$ & $\square$ & $\square$ & $\square$ & $\square$ & $\square$ & $\square$ & $\square$ & $\square$ & $\square$ & $\square$ & $\square$ \\
\hline \multirow{3}{*}{ 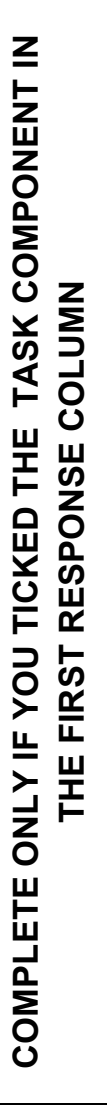 } & 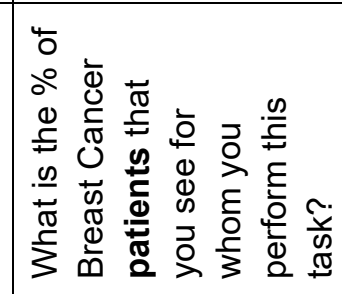 & ১ & ১0 & $\alpha^{\circ}$ & $\alpha^{\circ}$ & ১ & ㅇ & 。 & o & ১ீ & ১ீ & o & $\alpha^{\circ}$ & ১० & $\partial^{\circ}$ \\
\hline & 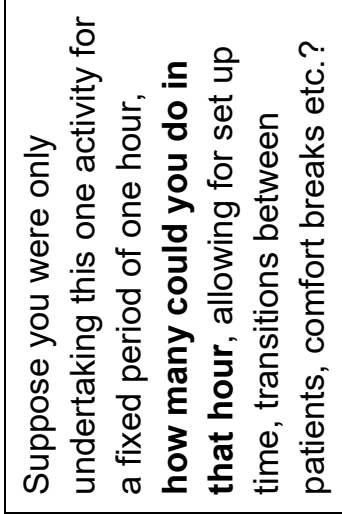 & & & & & & & & & & & & & & \\
\hline & 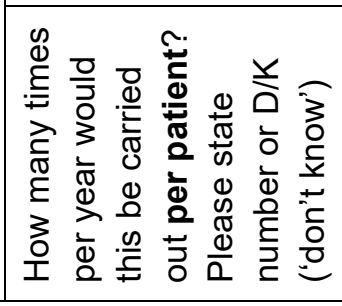 & & & & & & & & & & & & & & \\
\hline \multicolumn{2}{|c|}{ 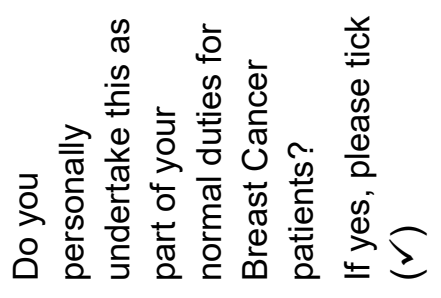 } & $\square$ & $\square$ & $\square$ & $\square$ & $\square$ & $\square$ & $\square$ & $\square$ & $\square$ & $\square$ & $\square$ & $\square$ & $\square$ & $\square$ \\
\hline & 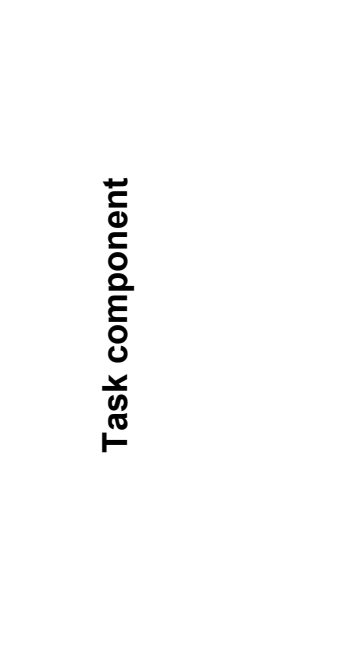 & 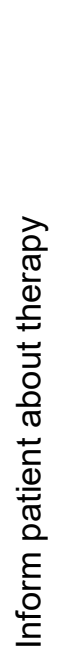 & 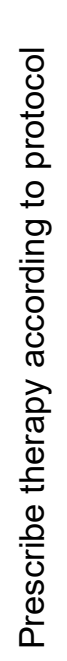 & 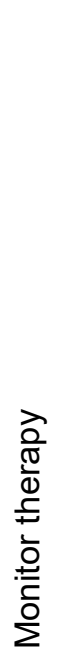 & 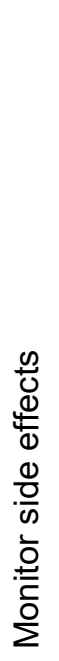 & 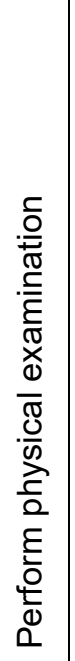 & 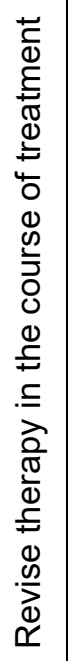 & 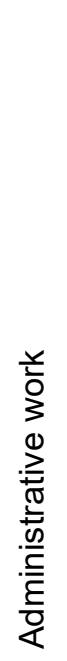 & 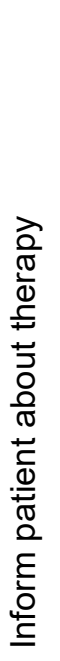 & 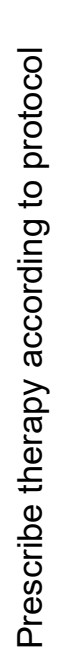 & 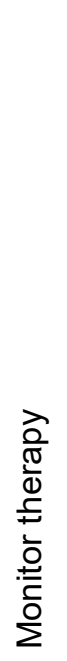 & 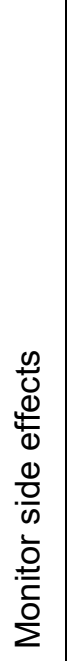 & 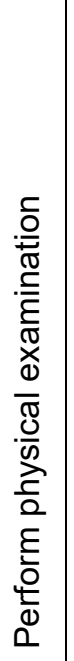 & 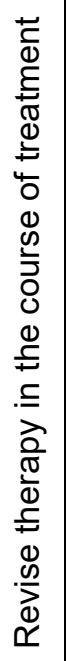 & 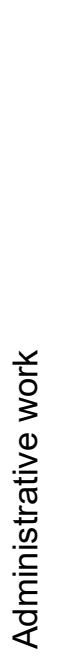 \\
\hline \multicolumn{2}{|r|}{$\begin{array}{l}\frac{x}{0} \\
\stackrel{D}{\sigma} \\
\mapsto\end{array}$} & \multicolumn{7}{|c|}{$\begin{array}{l}\text { Кделәчғ ןеиошлоч } \\
\text { /әи!ıюори }\end{array}$} & \multicolumn{7}{|c|}{ 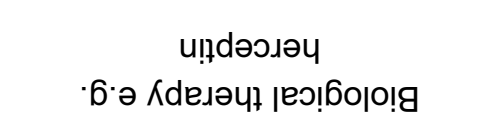 } \\
\hline
\end{tabular}

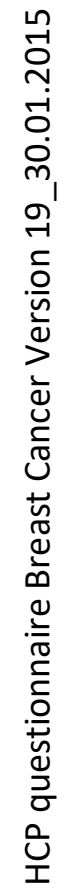




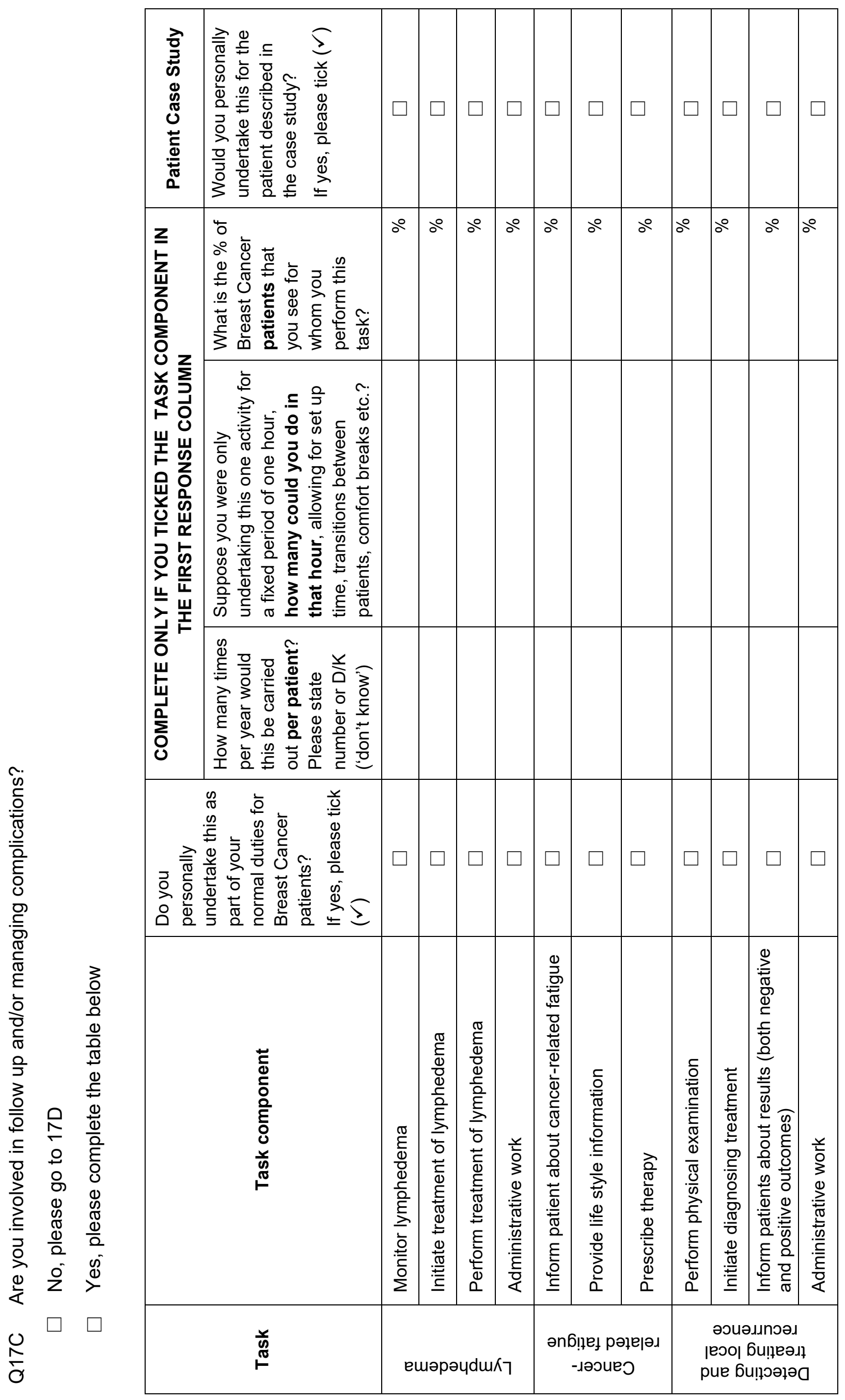

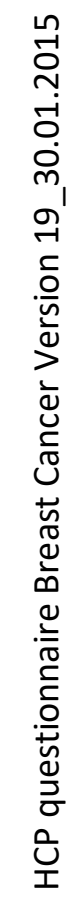




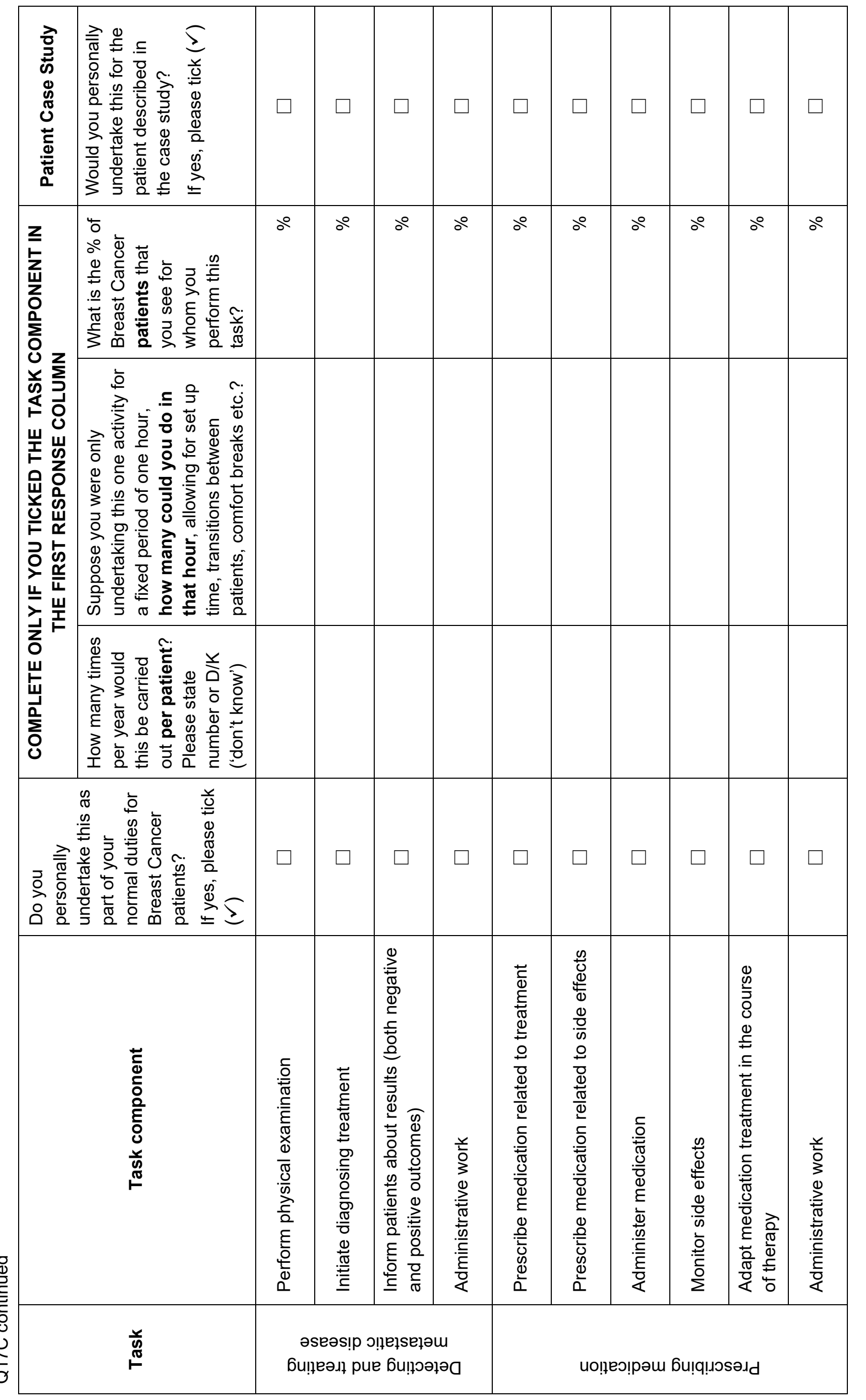

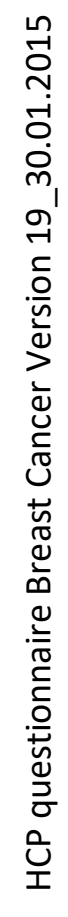




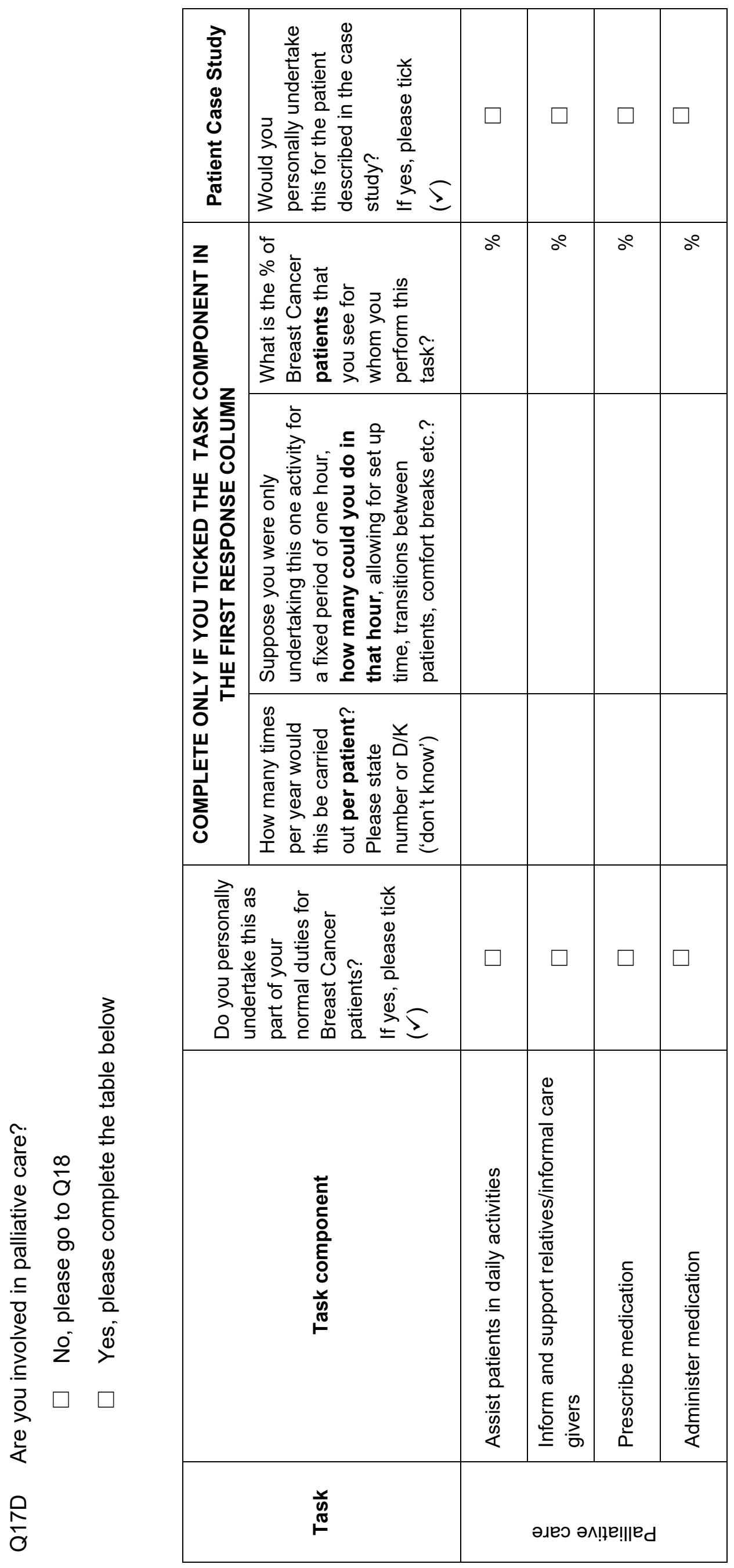


Study ID

\begin{tabular}{|l|l|l|l|l|l|l|l|l|l|l|l|l|l|}
\hline & - & & & - & & - & & & & & & - & \\
\hline
\end{tabular}

\section{Health Care Reform: the iMpact on}

practice, oUtcomes and costs of New roles for health pROfeSsionals (MUNROS)

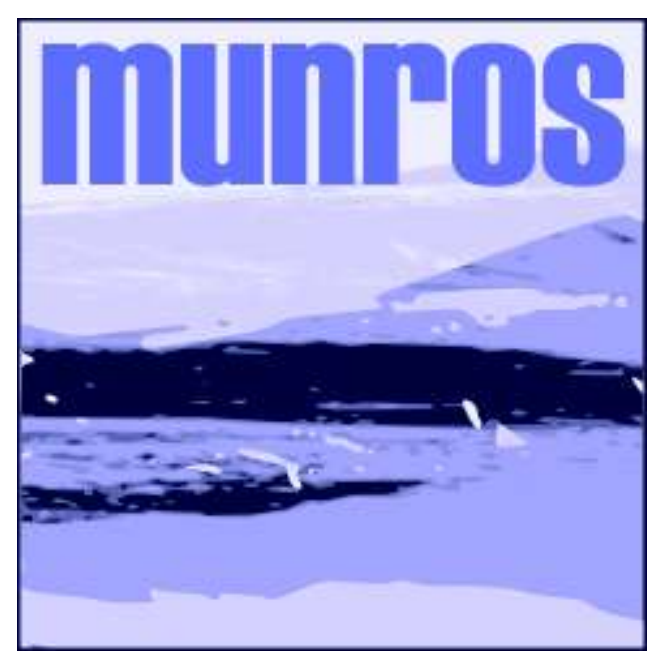

Health Care Professional Questionnaire (Heart Disease)

All responses will be treated with complete confidence

Please try to complete the whole questionnaire even though some questions may appear similar 
HCP questionnaire Heart Disease Version 19_30.01.2015 


\section{MUNROS Health Care Professional Questionnaire (Heart Disease) \\ Task list question (Q17) only}




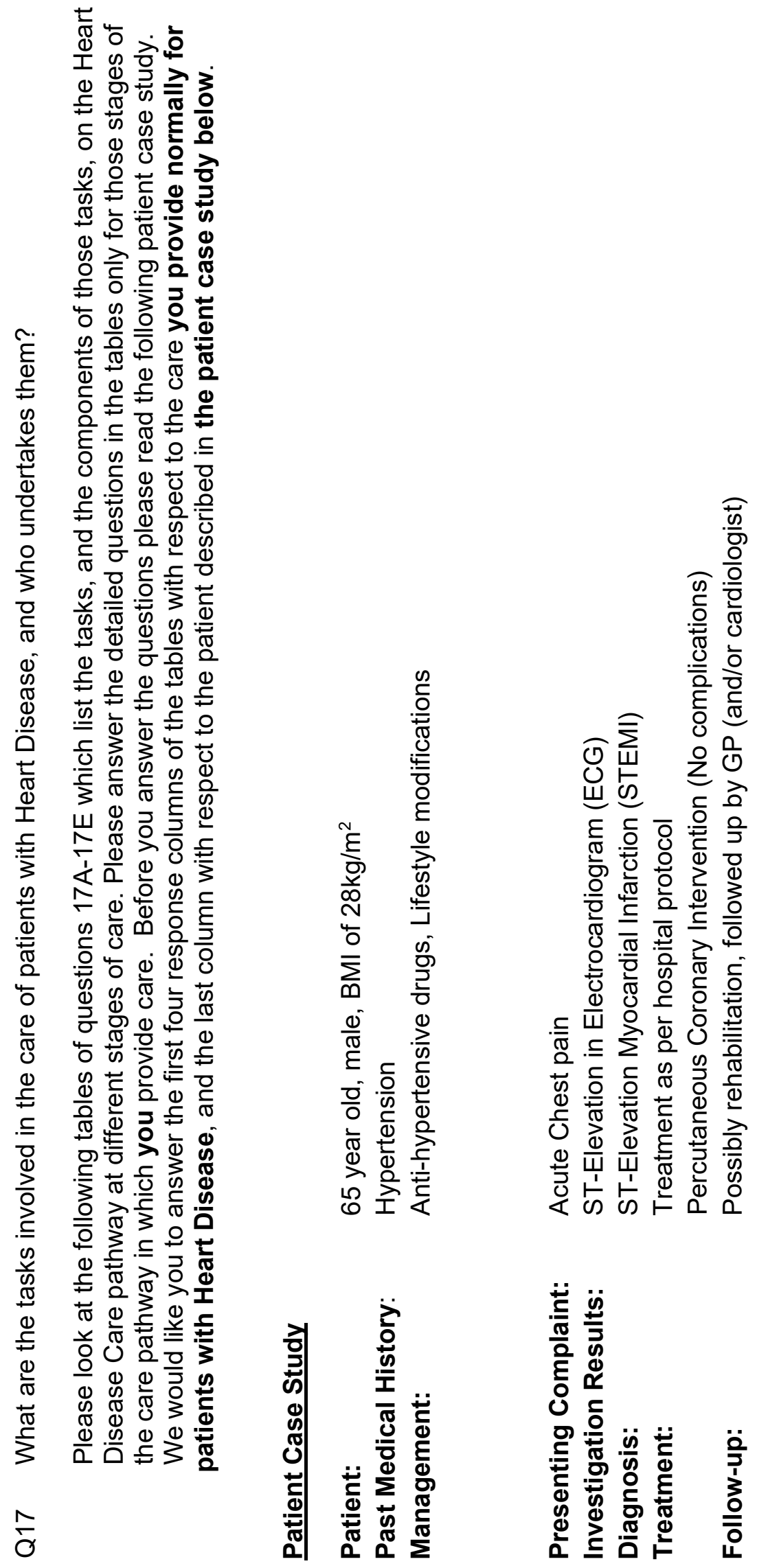




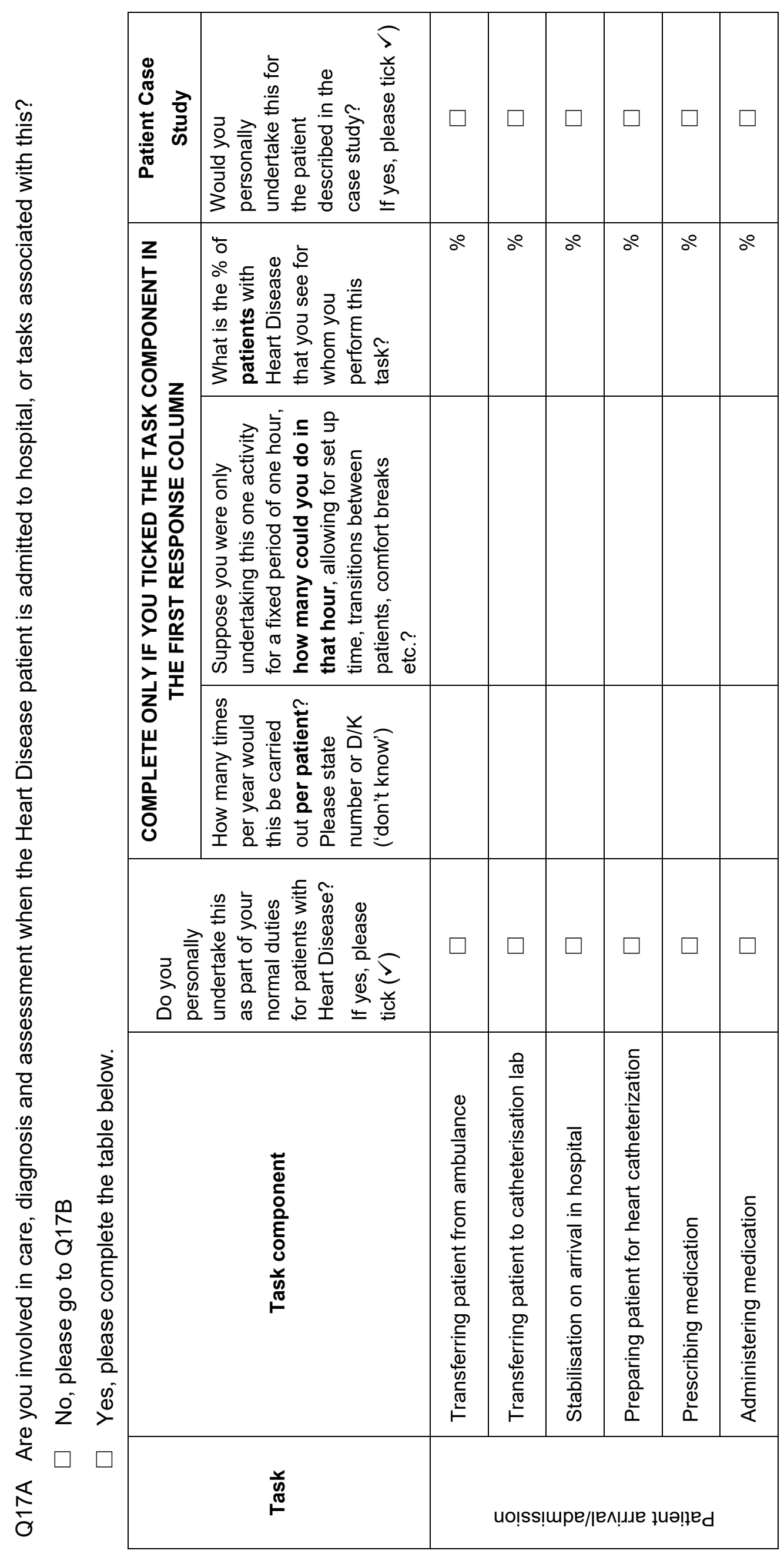

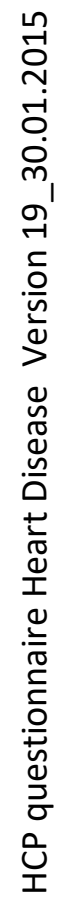




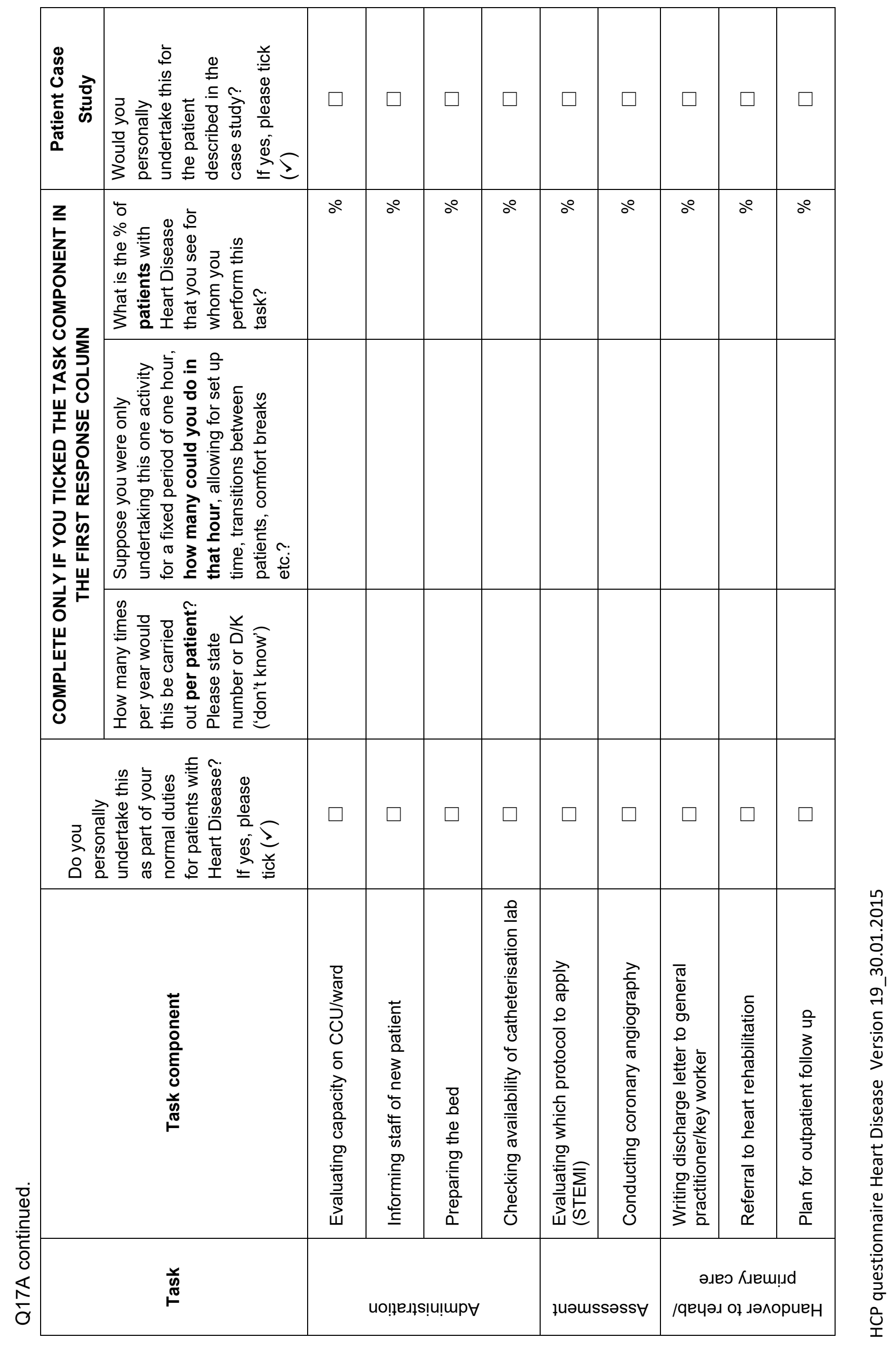




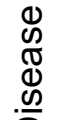

离

I

受

농

范

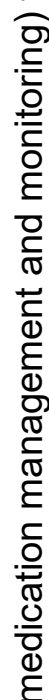

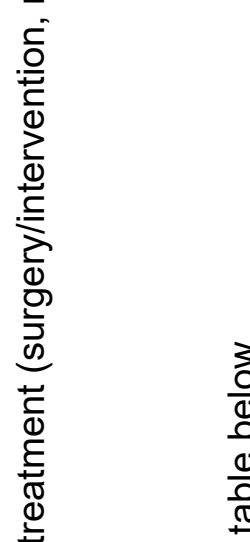

矛苍

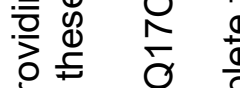

흘을

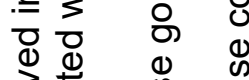

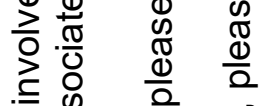

उ) 0

0

$\stackrel{m}{\frac{m}{\sigma}}$

西

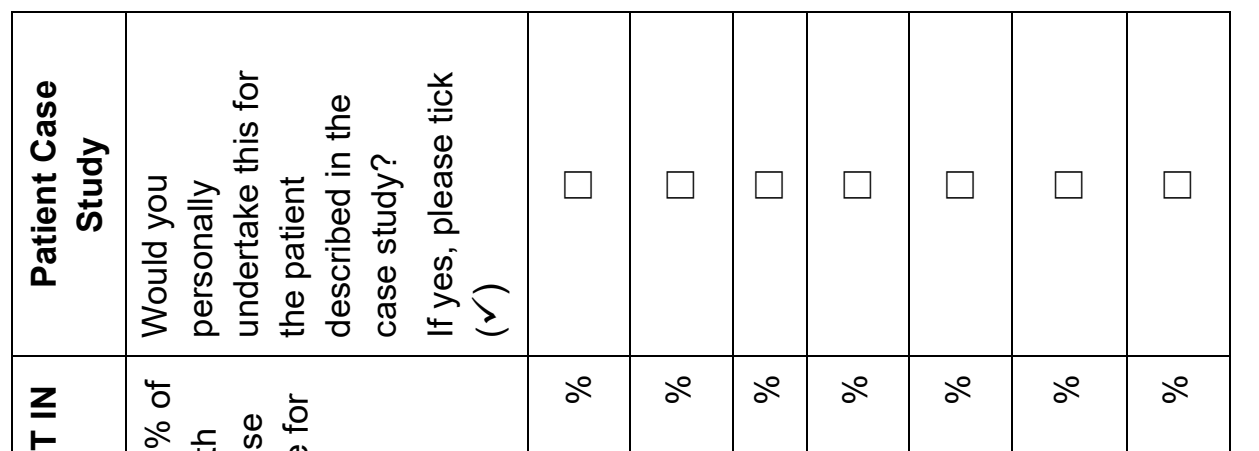

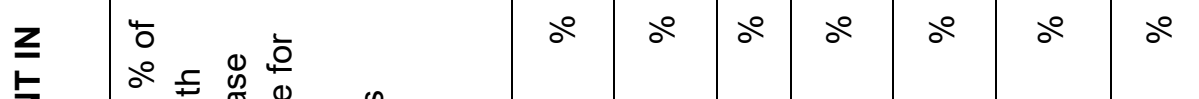

岸

O

落

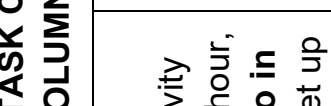

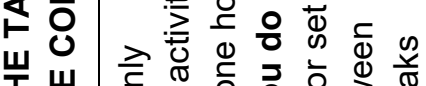

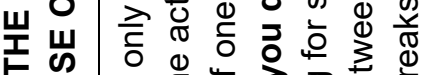

乙

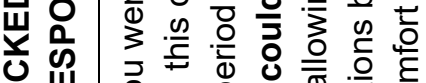

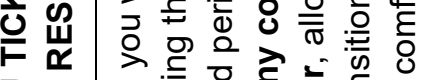

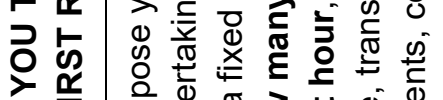

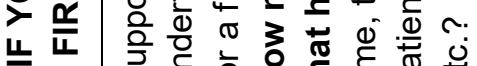

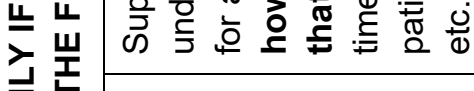

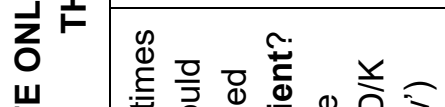

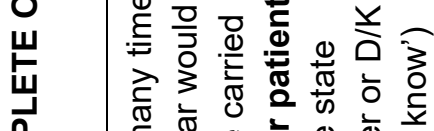

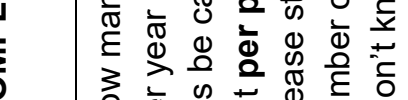

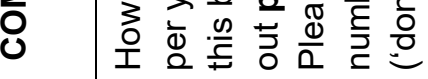

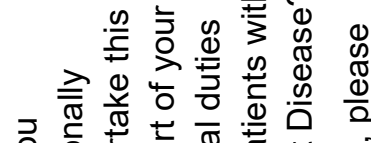

ठํ.

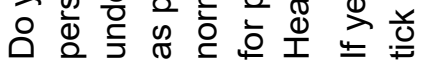

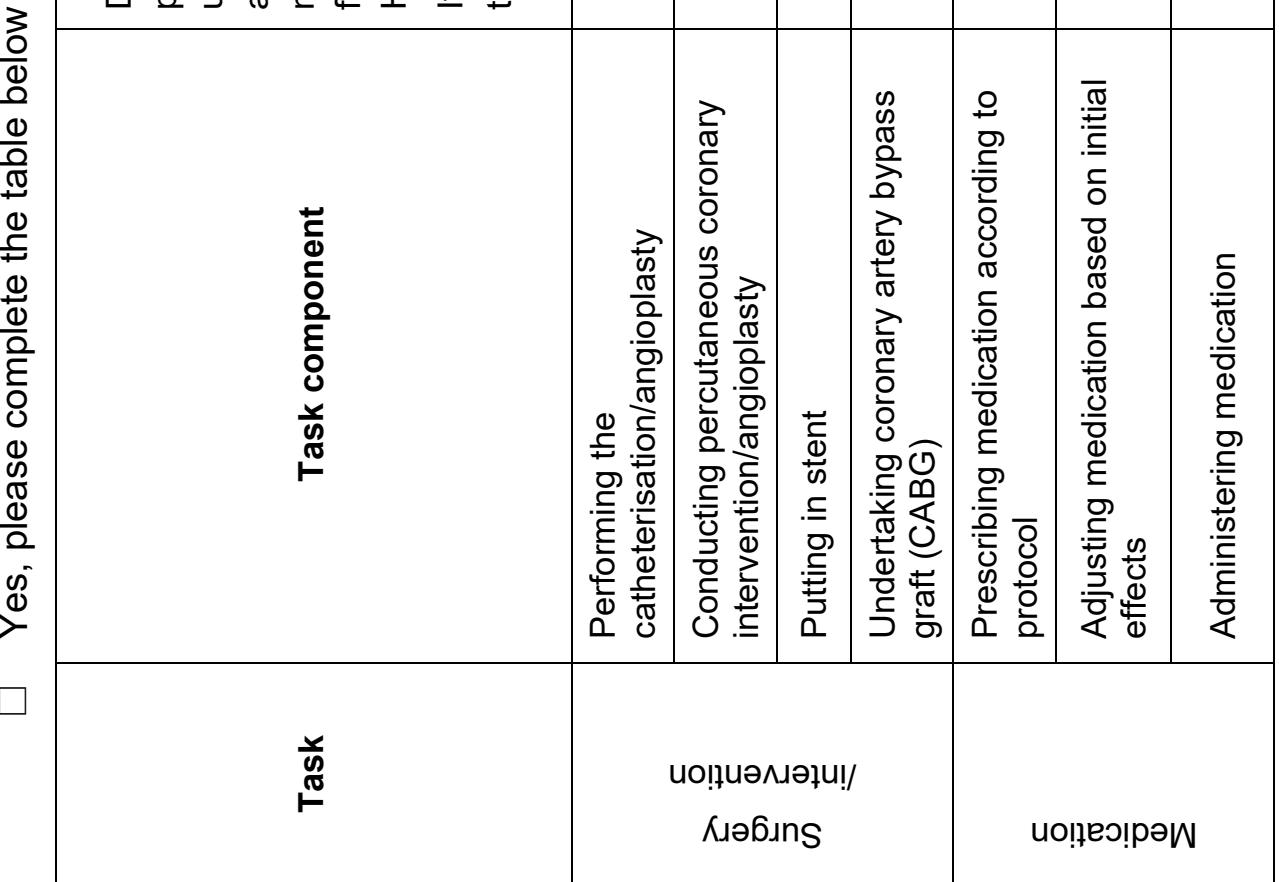

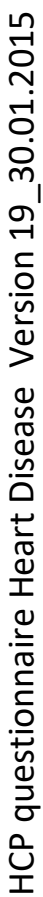




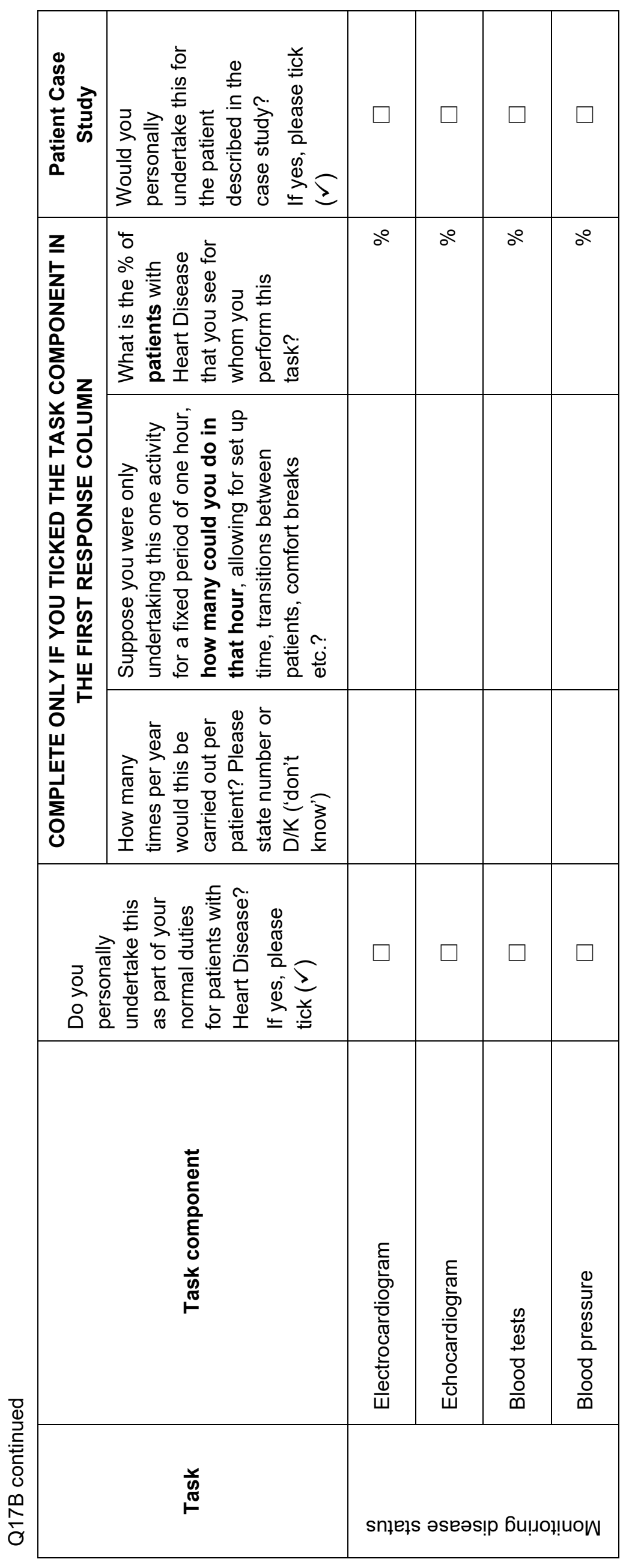




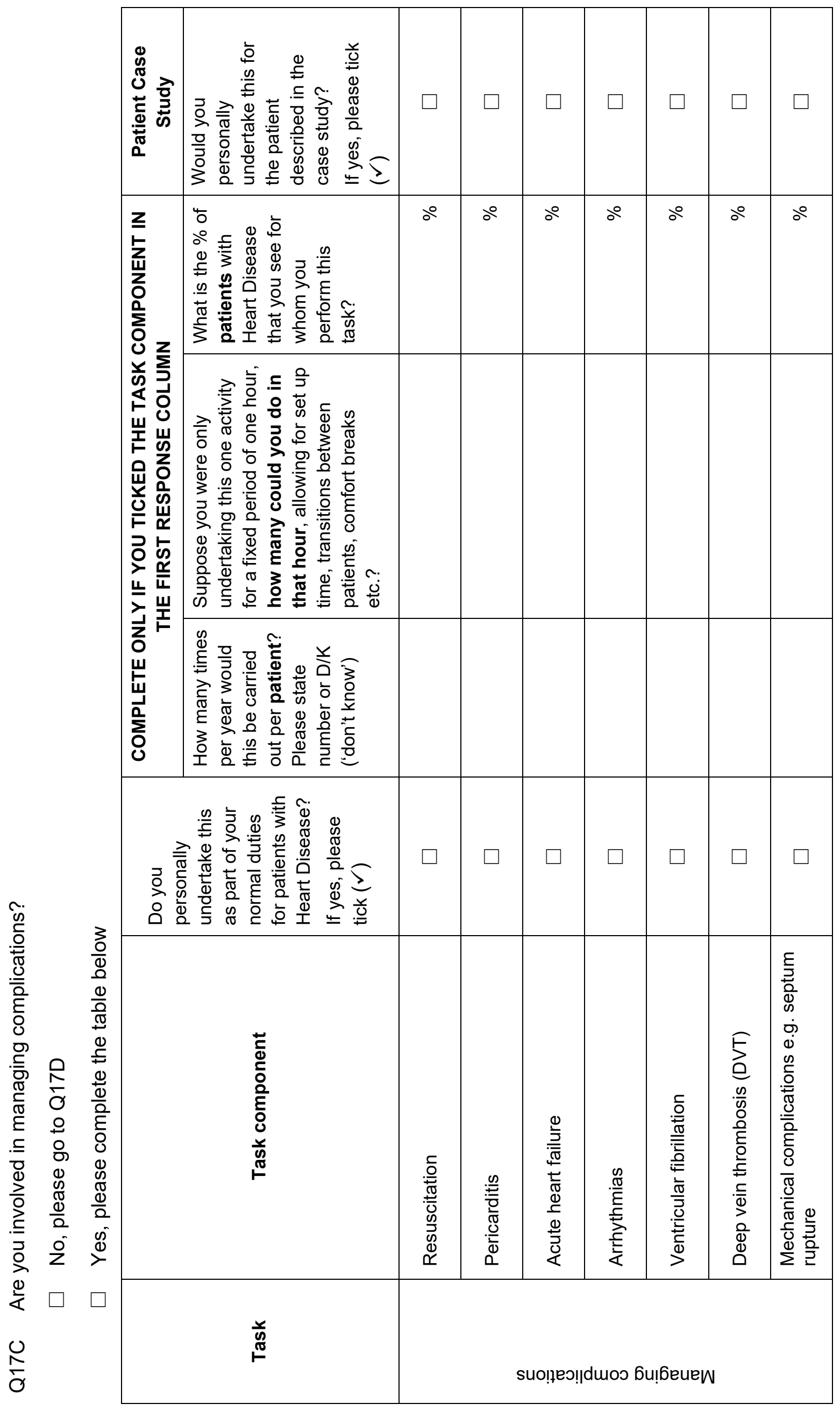

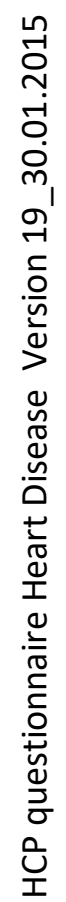




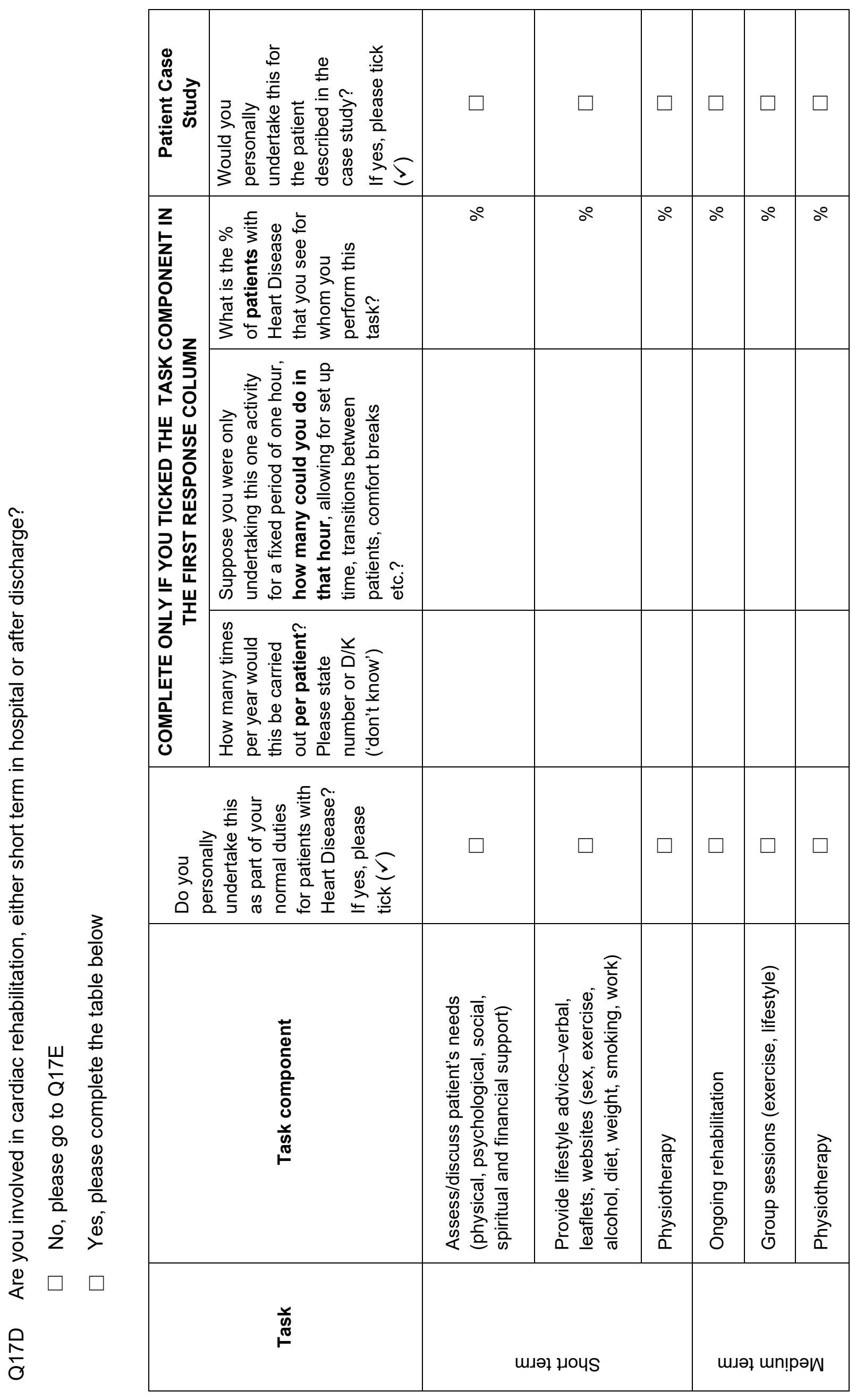

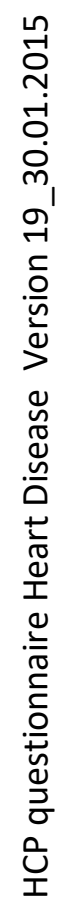




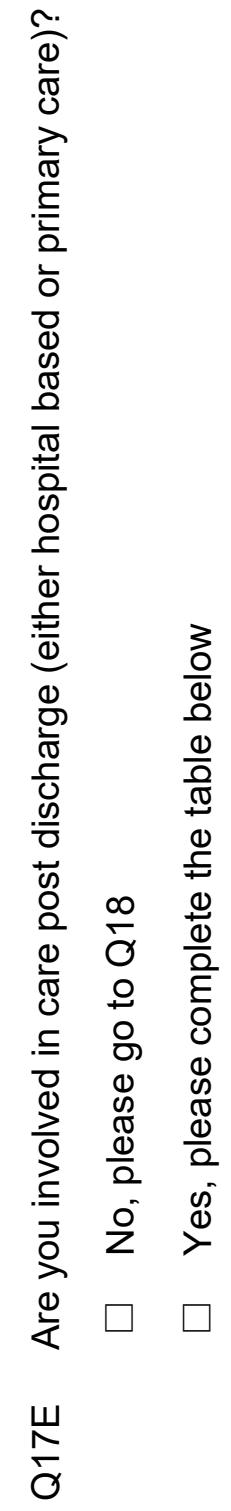

\begin{tabular}{|c|c|c|c|c|c|c|}
\hline 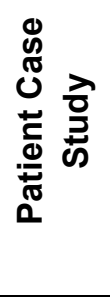 & 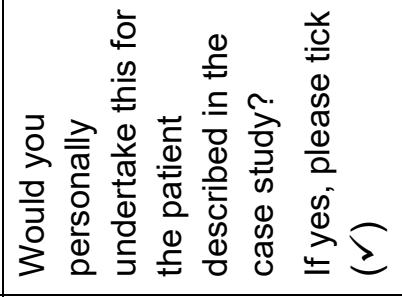 & $\square$ & $\square$ & $\square$ & $\square$ & $\square$ \\
\hline \multirow{3}{*}{ 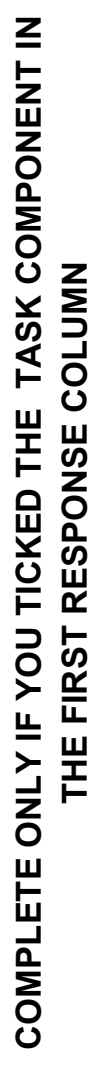 } & 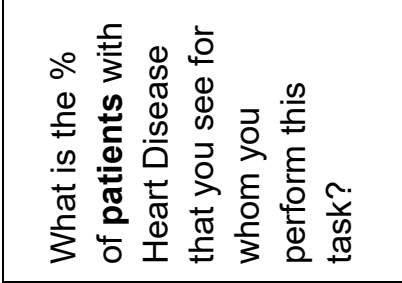 & $\circ^{\circ}$ & $\circ^{\circ}$ & $\circ^{\circ}$ & $\circ^{\circ}$ & $\AA^{\circ}$ \\
\hline & 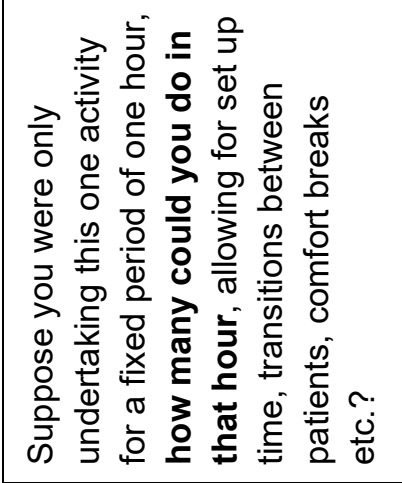 & & & & & \\
\hline & 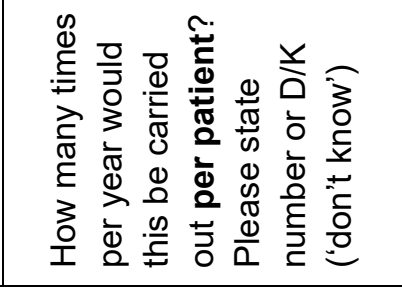 & & & & & \\
\hline \multicolumn{2}{|c|}{ 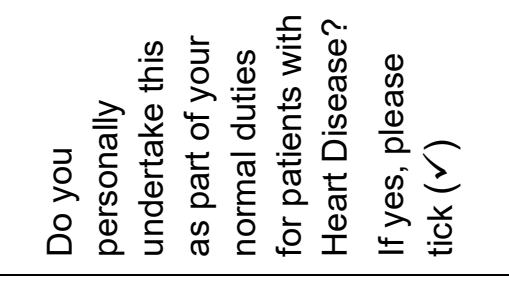 } & $\square$ & $\square$ & $\square$ & $\square$ & $\square$ \\
\hline \multicolumn{2}{|r|}{ 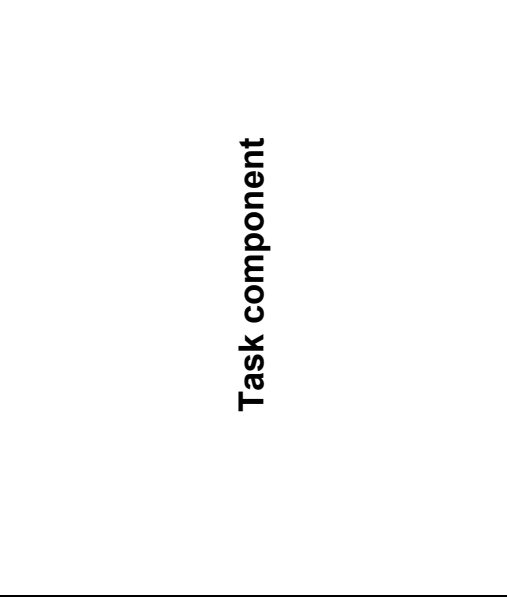 } & 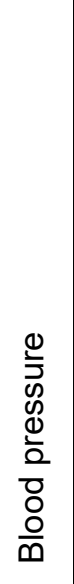 & 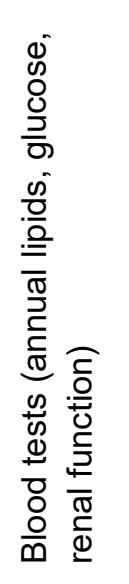 & 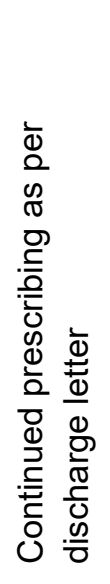 & 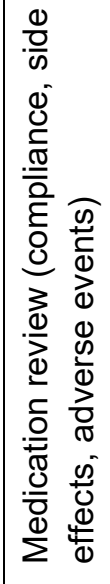 & 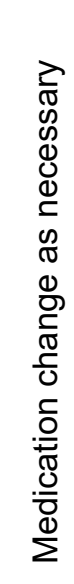 \\
\hline \multicolumn{2}{|r|}{ 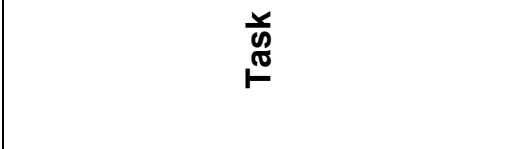 } & & 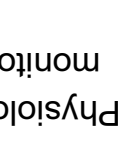 & \multicolumn{3}{|c|}{ 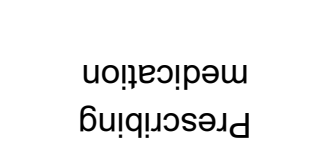 } \\
\hline
\end{tabular}




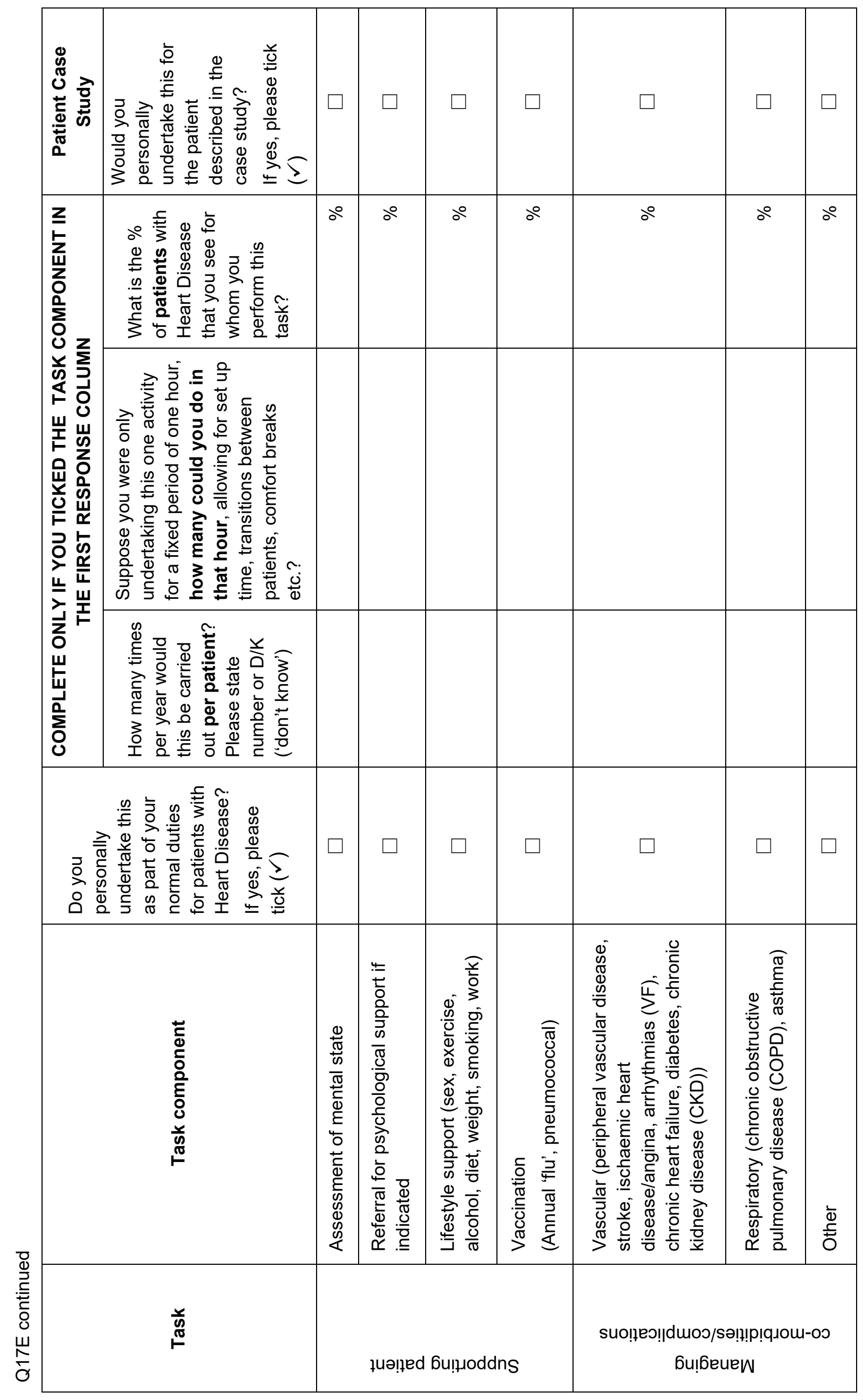

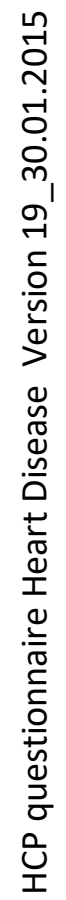

